\title{
A Controlled Material Flow Forming Mechanism of Curve Cutter Forging in The Hot Impression Forging of The Medical Instrument
}

Yiin-Kuen Fuh ( $\nabla$ michaelfuh@gmail.com )

National Central University

Chi-Peng Chen

National Central University

Wei-Li Wu

National Central University

Ming-Shiou Ho

National Central University

Ching-Shiang Tzeng

INTAI Industrial Co.,Ltd,Taichung City

\section{Research Article}

Keywords: Finite element method, hot forging, 3D overlay scanning, forging parting line, controlled material flow forming

Posted Date: November 19th, 2021

DOI: https://doi.org/10.21203/rs.3.rs-1072763/v1

License: (c) (1) This work is licensed under a Creative Commons Attribution 4.0 International License. Read Full License 


\section{Abstract}

In this study, a forming process during producing medical surgery curve cutter stapler would be tentatively as well as numerically investigated and validated by the simulations. The reasons for the investigation are to find the critical technology of the forming process and to understand this medical tool head forming within the forming process associated with medical surgery curve cutter stapler and improve the traditionally forming process. Moreover, to understand the medical tool head forming, the novel forging process, and the parting line approach are offered and simulated by the FE software QForm, the method data on the medical tool head forging are investigated and compared with the experimental analysis. According to the outcomes of the simulations, the distributions of the forming process, some parameters have been gotten to explain and improve these microscopic phenomena. The precision of the numerical patterns has been confirmed by comparing them with the test dimensions. The offered revised model from the forming preform has been submitted to achieve an alike forging condition when reducing manufacturing cost After the improved method, measure the shrinkage width of the workpiece. Compared with the product of the traditional process, the widest area is $6.37 \mathrm{~mm}$ shrink to $6.29 \mathrm{~mm}$. The shrinkage is about $1 \%$. Compared with the previous result is $5 \%$, the improvement plan has been optimized the outcomes very much.

\section{Introduction}

The outcomes explained the related density of the forming linking rod at the center shank was modified in contrast to the related parameters in some zones. Furthermore, the related density of the linking rod was reactive to the critical data. For example the forming speed and the original density of the workpiece. The best forming data are defined and offered by utilizing an orthogonal plan approach. The study recommends that the process data will be improved for a linking rod with alike the distribution of the density and will benefit to better get the demands of the linking rod industry [1]. To validate the results of this FE investigate method, a forming examination of the gear was executed, and the shifts of the die and formed workpiece were estimated utilizing an estimating device. Furthermore, the shape change of the gear improves in the outline direction of the tooth and declines in the lengthwise direction of the tooth. Lastly, the simulation outcomes exactly agree with the test outcomes, verifying the FE investigation approach offered in this study [2]. The modeling outcomes explain that in examined situations the distributions of deformation data were inhomogeneous within the forming. The data were seen at the specific area of the forming. The inhomogeneous deformation happened in the death metal area next to the dies [3]. The FEM outcomes determined that both data influence the stress of the die and the principal stress of the novel form near the fracture region decreases due to pre-compression stress of the zone. Lastly, the numerical analysis outcome was verified by research at the real process, and it was discovered the life of the die is increased more than 17 times [4]. The affection of process data was estimated, the forming load was estimated for chosen sizes of the standard workpiece and the original temperature (preheating) [5]. The material flow action and the temperature changes of the process are determined by utilizing FE investigation. Recording the deformation behavior from the forced displacement. The pattern 
to execute a hot non-isothermal forming of the steel. The nice choice has finished between the predicted parameters and the experimental outcomes [6]. The forecasts from the simulated patterns, which were utilizing different theories of the material and die to compare with each other. To inspect the correlation between the maximum stress values and forging load data, to unveil the influences of the material and the die patterns in finite element forecasts. The differentiation in forging load, the stress of the die, and the variety with time amongst the condition was defined quantitatively for the various die and the material patterns, to contribute the perspective for metal forging and the researchers [7]. At every stage of the forming process, the strain chiefly is discovered at the workpiece with the plastic deformation, showing a visible phenomenon of recrystallization. The grain size of the workpiece: $150 \mu \mathrm{m}$, which will be refined to $45 \mu \mathrm{m}$ after forming process. The Finite Element pattern coupling the recrystallization patterns can present some suggestions for optimizing the data of the forming process of the workpiece [8]. A small variation in the preloading outline was presented. Numerical outcomes showed a variation from $597 \mathrm{MPa}$ to $170 \mathrm{MPa}$ in the maximum stress. The adjusting of the model is presented in the manufacturing factory and the life of the workpiece increased obviously [9].

This study could be utilized to define the subsequent features: the curve of the tool wear and the possibility of the defect in the forming process. The offered method will be a valuable and useful tool that provides a fast estimate of the tool condition and forming quality. It may work for an apparatus to investigate the stability of the forming process [10]. An investigation of the material growth indicated a loss of the workpiece on the devices. The completed investigations explained the geometrical features of the defect of the forming process of the device, the measures at the forming process. The threeDimension scanning approach generated by the investigation has been regularly tested, which is proved by many kinds of research and applications. The achieved outcomes connected with SEM examinations and microhardness analyses explain the improvement of the life of the forming tool [11].

The counter-bore die is presented and executed to reduce the cracks. The existing work estimated the feasibility of the metal with friction drilling as well. It is discovered the condition, which can execute friction drilling to generate a weld joint by the two metal sheets [12]. The FE examination was executed for several material temperatures and friction data and to eliminate forming defects. Lastly, the forming experiment was performed for the original workpiece offered by three various designs to validate the analytic outcomes and reduce the defects of the forming process. The outcomes explained the friction was determined by the effective strain during the finite element investigation and the crucial parameter to improve friction is nearly $1.5-1.8$. Besides, the three various workpieces, the workpieces could eliminate the forming defect by improving the uniformity of the lubricant of the surface [13]. Cracking made from the phase particles was developed in the stirred area, it will disappear after the forming process [14]. In contrast to the condition of 0 o device slope angle, a tilted device offers a huge forming impact at the trailing side, the bigger area of high temperature at this region, higher temperature, and a more concentrated material flow next to the tool [15].

\section{Specification Of Medical Surgery Curve Cutter Stapler}




\subsection{Practical specification of medical surgery curve cutter stapler and defects investigation of traditional forging and aluminum extrusion}

Table 1

Chemical composition of AA 7075

\begin{tabular}{|c|c|c|c|c|c|c|c|}
\hline AA 7075 & $\mathrm{Fe}$ & $\mathrm{Mn}$ & $\mathrm{Si}$ & $\mathrm{Cu}$ & $\mathrm{Mg}$ & $\mathrm{Cr}$ & $\mathrm{Zn}$ \\
\hline (wt-\%) & $\leqq 0.5$ & $\leqq 0.3$ & $\leqq 0.4$ & $1.2 \sim 2$ & $2.1 \sim 2.9$ & $0.18 \sim 0.28$ & $5.1 \sim 6.1$ \\
\hline \multirow[t]{2}{*}{$\begin{array}{l}\text { AA } 7075 \\
\text { Material } \\
\text { properties }\end{array}$} & $\begin{array}{l}\text { yield } \\
\text { point } \\
\text { (MPa) }\end{array}$ & $\begin{array}{l}\text { tensile } \\
\text { strength } \\
(\mathrm{MPa})\end{array}$ & $\begin{array}{l}\text { elongation } \\
(\%)\end{array}$ & $\begin{array}{l}\text { Young's } \\
\text { modulus } \\
(\mathrm{GPa})\end{array}$ & $\begin{array}{l}\text { hardness } \\
(\mathrm{HB})\end{array}$ & $\begin{array}{l}\text { Density } \\
\left(\mathrm{kg} / \mathrm{cm}^{3}\right)\end{array}$ & \\
\hline & $\geq 455$ & $\geq 524$ & $9-10 \%$ & 71 & 150 & 2.81 & \\
\hline
\end{tabular}

The carrier to be developed is a precision medical surgical suture gun, as shown in Fig. 1. This medicalsurgical suture gun has a cutting blade and an instrument head for automatic suture nails. It has both cutting and suture, Anastomosis can be achieved, reducing bleeding, eliminating traditional suture time, and speeding up recovery. This product is precision medical equipment, so the size and geometric tolerance specifications are very strict. However, due to the poor design of the old manufacturing process and pre-forming, it is easy to cause excessive residual stress on the workpiece, resulting in defects in processing deformation during subsequent processing. Research on minimization of secondary stress by improving the process and adopting the principle of volume distribution for the performing line to reduce the generation of excessive waste, and combined with the control of zone deformation to reduce the amount of deformation and thus reduce the residual stress in the workpiece.

The functional specification of the medical-surgical curve cutter stapler analyzed in this study was mainly composed of precision surface accuracy curve head (green color), cartridge module (yellow color), and retaining pin as schematically presented in Fig. 1(a). Fig. 1(b) presents the curve ahead of the curve cutter stapler and it was made of AA 7075. AA 7075(aluminum alloy) which chemical composition is shown in Table 1 is a heat-treated forging alloy with high strength and good fatigue strength and it was widely used in the production of clinical medical equipment. The design of the curved head of medical surgical curve cutter stapler aims with the local cutting and suturing such that the tissue has experimented has presented in Fig. 1(c) and Fig. 1(d) explains the operation mechanism of local cutting and suturing the tissue with the schematic diagram.

This experiment belongs to warm forging, and the workpiece will be preheated to 440 degrees celsius. Fig. 2. is the flow stress curve of the material AA7075 at 450 degrees celsius, showing that the work hardening in the first deformation step causes the stress to reach the peak strain in a short time. The distortion of the deformation gives the driving energy for dynamic recrystallization or recovery of softening continuous deformation, so its stress is reduced rapidly, and the peak stress rises with the increment of the strain rate and the declines of the molding temperature. Finally, under the interaction of 
work hardening and softening stress, the flow stress declines approximately linearly with the increase of strain.

Since the forging material developed in this case is AA7075, aluminum extrusion can be used for preforming as shown in Fig. 3., and the desired shape can be achieved through subsequent processing. During the manufacturing process, there will be residual stress in the workpiece. This condition will cause the product to shrink in the thinner part during the processing. This shrinkage has seriously affected the moldability of the finished product.

Traditionally curve cutter staplers are routinely manufactured by aluminum extrusion and CNC because of the facts that fine surface finish and aluminum alloy's good extrusion ability. The extrusion process was presented in Fig. 3 (a) and Fig. 3 (b), respectively front side and the contrary side. However, the residual stresses were generated at the thinner region of the workpiece during the high-temperature extrusion process. Due to the inadequate residual stress distribution, the shrinkage, shown in Fig. 3 (c), leads that the width of the workpiece was decreased from $6.38 \mathrm{~mm}$ to $6.02 \mathrm{~mm}$, nearly $5 \%$.

The traditional manufacture of curve cutter heads by forging is shown in Fig. 4. At first, the forging process was aimed at reducing the residual stress, however, as Fig. 4. shows, the scrap material was over $50 \%$. Due to that, the traditional process design causes material flow bad, and performing without volume distribution analysis leads to unnecessary waste. Because of the above reasons, the overload during the one-step forming process decreases the lifetime of forging die, and also the one-step forming process leads to major residual stress with excessive deformation. To reduce the residual stress, and due to the aluminum extrusion material, it has the disadvantage that the same batch of materials cannot be used. In addition, the forging process is a one-time molding, which leads to excessive deformation and excessive residual stress. Therefore, the improvement case will base on performing volume distribution and process design to replace the original process.

The product developed in this case mainly measures the size and geometric tolerances by 3D scanning profile. Define the pros and cons of the workpiece during the forging process. Fig. 5 (a) and Fig. 5 (b) are the results of the benchmark fitting 3D scanning of the medical tool in the traditional manufacturing process. Compared with the CAD drawing file of the product, the positive value means that the part exceeds the area defined by the CAD drawing file, and the negative value is the opposite.

As a result, due to the result of residual stress during processing. $80 \%$ of the area profile error is greater than the test value range of $0.01 \mathrm{in}$, resulting in black color, only the lower part, which is red but still does not meet customer specifications as presented in Fig. 5 (a). Fig. 5 (b) is the back scan after the cutting edge. The outcomes show the lower mold is fixed leads to most of the area being within plus or minus 0.003 in. The real workpiece defects are shown in Fig. 5 (c).

The part as Fig. 6. shown is the engineering drawing of the curve cutter head, the geometric dimension needs to be highly precise especially the B1 in Fig. 6 (b) with the shrinkage easily occurred, which were strictly limited to $1 \%$ relative error. Fig. 6 . shows the most critical of the final product, presumably 
containing the top view dimension (A1:52mm 57mm A2:93mm 98mm A3:15mm 16mm A4:38mm 40mm A5:38mm 41 $\mathrm{mm}$ ), cross-section dimension (B1:11 mm 13mm B2 B4 are confidentialities), side view-dimension $(27 \mathrm{~mm} \sim 29 \mathrm{~mm})$ and the partially enlarged view(A6:6 $\mathrm{mm} \sim 8 \mathrm{~mm}$ A7:5mm 7mm). The area marked by the red circle in Fig. 6 (a) is intended to increase the strength of the workpiece to prevent the deviation of the two ends during forging. This part will be removed during subsequent processing. Ideally, the entire contour maintains the B1 size. However, since the cutting process will be carried out in the middle, it is necessary to reduce the residual stress to reduce the deformation of shrinkage. The part size of the right view and the Partially enlarged size of the workpiece is presented in Fig. 6 (c) and Fig. 6 (d).

\subsection{Mechanism of reducing residual stress}

The three-pass forging in this new process is shown in Fig. 6. The purpose is to reduce the generation of residual stress and to eliminate residual stress during subsequent heat treatment. In the actual production stage of the temperature finish forging process, it is used It is carried out in stages, and all steps are not completed at once. Heating is still required in the middle of the pass. However, because the material of the workpiece is aluminum alloy AA7075, a protective oxide mold will be formed on the surface, so there is no need for sandblasting in the stage The actual development process is as follows: first, bend (Fig. 6 (b) ) and then perform the first rough forging (Fig. 6 (c) ). After the rough forging, the rough shape has been formed, and finally, the second finish forging (Fig. 6 (d) ) is performed to forge the workpiece for the customer. The required geometry, and then cut the edge to remove the waste around and inside, then the surrounding burrs can be ground and polished. In this pass, the two sets of molds are designed as one mold and two cavities. Both are designed to be pre-formed and fixed to avoid positional deviation when placing the workpiece.

Table 2 Parameters of numerical simulation of medical surgical curve cutter head

\begin{tabular}{|l|l|}
\hline Initial forging temperature $\left({ }^{\circ} \mathrm{C}\right)$ & 440 \\
\hline Preheating temperature of forging die $\left({ }^{\circ} \mathrm{C}\right)$ & 200 \\
\hline Material of work piece & AA 7075 \\
\hline Material of forging die & H 13 \\
\hline Environment Temperature $\left({ }^{\circ} \mathrm{C}\right)$ & 20 \\
\hline Heat transfer coefficient $\left(\mathrm{W} /\left(\mathrm{m}^{2} \cdot k\right)\right)$ & 30 \\
\hline Friction factor & 0.3 \\
\hline
\end{tabular}

In the simulation of the finite element software, the machine parameters and boundary conditions are consistent with the actual forging as shown in Table 2. The result is similar to the actual forging product. The appearance of the finished product and the trend of burrs are similar, indicating that the two are fully consistent; It can be seen from the geometry of the workpiece that the height of the burr is inconsistent, and some places can be adjusted. Therefore, the following research will adjust the overall thickness to achieve more results. 
The detailed tools of the forging die are shown in Fig. 8 (a) Fig. 8 (d), which are used for the warm forging process. According to the pass design, the mold is divided into two groups of molds, both of which are one mold and two cavities. The mold structure is mainly divided into bending forming, the first pass (rough forging), and the second pass (fine forging). Using precision stamping machine and precision mold design, by optimizing the material flow behavior, reducing the flash design area on the mold, the tonnage of the process can be reduced.

To improve some deficiencies of the forming process, this research intends to use precision performing with a warm forging process, This forging process uses preforms with volume distribution as shown in Fig. 9 (a). Each size as Fig. 9 (b) and Fig. 9 (c) shows A1: 41 43mm, A2: 62 65mm, A3: 25 27mm, A4: R14 16mm, A5: 45 48mm, A6: 1mm 2mm, A7: R13 14mm, and A8: 2 3mm; Fig. 9 (c): B1: 92 95mm and B2: 97 99mm; C: C1: 75 77mm, C2: 38 40mm, C3: 12 13mm andC4: 10 14mm) laser cutting preforms, preforms with volume distribution are produced in the forging process. Compared with the waste before, the scrap material waste is reduced by $90 \%$, and it is more accurate in local forming. The efficiency of molding is also increased.

\subsection{Numerical analysis of medical surgery curve cutter head forming}

Following the forming process, the mold temperature increases with the influence of the temperature of the material and plastic deformation. The highest die temperature is going to reach $\sim 380{ }^{\circ} \mathrm{C}$ as presented in Fig. 10 (a). Due to the pressure of the die with the acute plastic metal flow, and the continued connection time, which cause the edge of the die of highest temperature simulated. In this die, the temperature distribution plastic deformation progressively declines from the region of the edge of the die to the central area of the workpiece as exhibited in Fig. 10 (b). The other area of low temperature locates in the cavity of the central part of the die and the reason is opposite to the previous region, a few metals flowing leads to the heat can not be concentrated during the forming process.

The relative deformation situation is shown in the forming process, as explained in Fig. 11 (a). The workpiece was preheated to $\sim 440^{\circ} \mathrm{C}$ first. While the stroke of the punch was $80 \%$, the top die moves to descend and connect with the workpiece. The profile of the medical tool is formed on the material when punch stroke was $90 \%$. The medical tool has finished the required forming level and achieved the final forging height while the stroke was $100 \%$. Fig. 11 (b) explained the effective strain distribution of the final forming workpiece is calculated to reach above 0.65 . Moreover, the highest stress values almost reach $150 \mathrm{MPa}$ and are mainly distributed around the bumps, as shown in Fig. 11 (c). During the forming process, with the moving downward of the top die to the workpiece, the region of the plastically deformed is risen on the die and the temperature increase due to the flowing resistance of the material in the edge of the die, the distribution of temperature of the final forming workpiece on the surface reached $500{ }^{\circ} \mathrm{C}$, as presented in Fig. 11 (d).

According to the suitable finite element analysis software (QForm), the simulation analysis software of the forming process can present the results of the metal volume forming of the process. In addition, it 
also gives a full forming process simulation solution for most of the cases. Numerical methods can be used to reproduce various phenomena during forging, and the results of temperature and stress can also be analyzed and improved, to solve the profile and size Tolerance issues, this research analyzes and tracks the average stress generated by the workpiece during the forming process, and analyzes the five points where the maximum stress is inferred (as shown in Fig. 12 (b)) at different strokes and produces a stress stroke diagram (As shown in Fig. 12 (a)), Fig. 12 (c) is a cross-sectional view of the corresponding molding for the five characteristic peaks in the stress stroke diagram. The highest stress value will fall at the position of point $A$ when the local bump is formed, and the value is up to $-534 \mathrm{MPa}$. The reason is that the highest stress concentration occurs in the place with the most strain in the entire forming process. The third point in Fig. 12 (c) is that the mold and the front and rear ends of the workpiece contact first, resulting in stress in the middle part. In the forging process, due to a large amount of strain, the larger the stress value, especially the local bumps.

\subsection{Simulation results and discussion}

To analyze the deformation of the workpiece, eight points are chosen at each location near the surface and the bump (P1, P2 ..., P8), as explained in Fig. 13 (a) Fig. 13 (c). Especially, P4 to P6 are located at the top of the local bump, the minimum effective strain is discovered in these areas. By comparing the analyzed of the region of the effective strain, temperature, and effective stress relationships of these regions, the related influence of the forming process data at the forging of the medical tool should be investigated further. To detailedly demonstrate the distribution of the strain at per point of the workpiece, as shown in Fig. 13 (d).

The simulation outcomes explained the maximum strain rises from the surface of the workpiece (P1) to the top of the bump (P4 to P6) in this area, and the chiefly reason is that the deformation situation of material flowing is relatively acute at this area of the bump, which is also explicitly shown in Fig. 13 (d). Furthermore, in the surrounding area (P1 P3, P6 P8) of the bump of the points, the plastic strain is severe usually. Hence, the results of the effective plastic strain progressively rise from the surface to the bump.

To solve the stress problem, optimize the preform workpiece corresponding to a large amount of deformation, and study the preform workpiece thickness, as shown in Fig. 14 (c). For the C4 position, five types of $12 \mathrm{~mm}, 11.8 \mathrm{~mm}, 11 \mathrm{~mm}, 10.7 \mathrm{~mm}$, and $10.5 \mathrm{~mm}$ are made. Different thicknesses are studied and analyzed. $10.7 \mathrm{~mm}$ is the thinnest thickness available in the current study. After simulation and volume calculations without changing the pre-forming geometry, if the thickness is lower than this thickness, it will not be able to form smoothly. The sampling points are shown in Fig. 14 (b)., are located in the positions with the highest expected local bump deformation in sequence. The result is shown in Fig. 14 (a). If point $A$ is taken as the sampling standard, the thickness of $11.8 \mathrm{~mm}$ has the smallest stress value of $-495 \mathrm{MPa}$, and $10.7 \mathrm{~mm}$ is the highest stress value of about $-620 \mathrm{MPa}$. According to the analysis of the simulation results, the thickness of $11.8 \mathrm{~mm}$ is the closest to the required thickness of $11.7 \mathrm{~mm}$ (Fig. 14 (d)), so the deformation during molding is the least, which directly affects the stress analysis results. In addition, the thicknesses of $12 \mathrm{~mm}$ and $11 \mathrm{~mm}$ are also consistent with this Trend, the thickness of 
$10.5 \mathrm{~mm}$ is because the molding is not complete, so it has not yet entered the process of local bumps, resulting in lower stress. If the thickness of the preform is smaller than the thickness of the finished product, the forming method where the stress is greatest is to extrude the local bumps, otherwise, it is forging, but it still conforms to the stress analysis results.

\subsubsection{Outcomes and discussion of the improved workpiece}

Figure 15 (a) is a schematic diagram of the poor contour of the 3D overlapping scanning area. The figure shows that the surface contour of the workpiece in this study. The maximum positive value is 0.0021 such as the red frame area, and the minimum negative value is 0.0012 , they are all distributed near the open-end of the medical tool. These molding results will affect the assembly process of the workpiece in the future, as shown in Figure 15 (b). The workpiece cannot be placed in the fixture due to the poor contour of the molding. Therefore, the following situations need to be avoided in the molding design: 1 . Insufficient blank space of the forming area, as shown in Figure 15 (c) 2. Poor design of blank space during moldings, such as too many blanks or insufficient blanks as shown in Figure 15 (d), will cause defects, and follow-up plans will continue to improve the tool The open-end design is shown in Figure 15 (e), hoping to reduce the occurrence of poor molding dimensions.

Figure 16. is the diagram of the contour defects analysis of the medical device forgings in the study. Figure 16 (a), which shows that the poorly processed areas of the final forged products are mainly distributed in the four corners of the workpiece, which will cause the workpiece to be unable to be placed in the fixture, or assembling gaps and defects are presented in Figure 16 (b). Figure 16 (c) explained that the material flow when the forging process, especially the value of the part around the workpiece is close to zero, which means these areas will find some defects easily.

The contour improvement method of the medical forgings in this study is presented in Fig. 17, and the schematic diagram of rough forging and fine forging parting surface is shown in Fig. 17(a), and the result of changing the forging parting surface according to the manufacturer's requirements, the parting line was improved and shown in the circle of the green line to prolong the parting line longer and flatter than before model, and the outcomes and the defects of the workpiece at the final product are explained in Fig. 17(b).

According to the analysis results of the final forging product, the best pre-forming method is used to perform 3D scanning benchmark fitting (Fig. 18 (a) and Fig. 18 (b) ). The same is used to perform overlay analysis based on the scanning results. The results of measuring the front of the forging show that reducing the stress generated during forging is effective for the profile. About $70 \%$ of the middle section is effectively correct to below 0.003 (in), but in the upper and lower parts, although there are improvements in geometric dimensions, there are still some places that need to correct. The maximum error is 0.0062 (in) in the progress. After the improved method, measure the shrinkage width of the workpiece (Fig. 18). Compared with the product of the traditional process, the widest area is $6.37 \mathrm{~mm}$ shrink to $6.29 \mathrm{~mm}$. The 
shrinkage is about $1 \%$. Compared with the previous result is $5 \%$, the improvement plan has been optimized the outcomes very much.

\section{Conclusion}

The 3D finite element design of hot forging AA 7075 aluminum medical tool forming was built and investigated using QForm software by submitting the particular models achieved in the mechanical process of manufacturing a medical surgery curve cutter stapler. In this study, the conclusions can be discovered from the experimental outcomes, which are following:

(1) To improve some deficiencies of the forming process, this research intends to use precision performing with a warm forging process, laser cutting preforms, preforms with volume distribution are produced in the forging process. Compared with the waste before, the scrap material waste is reduced by $90 \%$, and it is more accurate in local forming. The efficiency of molding is also increased.

(2) The medical tool has finished the required forming level and achieved the final forging height while the stroke was $100 \%$. The effective strain distribution of the final forming workpiece is calculated to reach above 0.65 . Moreover, the highest stress values almost reach $150 \mathrm{MPa}$ and are mainly distributed around the bumps. The temperature increase due to the flowing resistance of the material in the edge of the die, the distribution of temperature of the final forming workpiece on the surface reached $500{ }^{\circ} \mathrm{C}$.

(3) This research analyzes and tracks the average stress generated by the workpiece during the forming process, and analyzes the five points where the maximum stress is inferred. The highest stress value will fall at the position of point $A$ when the local bump is formed, and the value is up to -534MPa. The reason is that the highest stress concentration occurs in the place with the most strain in the entire forging process.

(4) To solve the stress problem, optimize the preform workpiece corresponding to a large amount of deformation, and study the preform workpiece thickness. For the $\mathrm{C} 4$ position, five types of $12 \mathrm{~mm}$, $11.8 \mathrm{~mm}, 11 \mathrm{~mm}, 10.7 \mathrm{~mm}$, and $10.5 \mathrm{~mm}$ are made. Different thicknesses are studied and analyzed. If point $A$ is taken as the sampling standard, the thickness of $11.8 \mathrm{~mm}$ has the smallest stress value of $-495 \mathrm{MPa}$, and $10.7 \mathrm{~mm}$ is the highest stress value of about $-620 \mathrm{MPa}$. According to the analysis of the simulation results, the thickness of $11.8 \mathrm{~mm}$ is the closest to the required thickness of $11.7 \mathrm{~mm}$, so the deformation during molding is the least, which directly affects the stress analysis results.

(5) According to the analysis results of the final forging product, the best pre-forming method is used to perform 3D scanning benchmark fitting. The results of measuring the front of the forging show that reducing the stress generated during forging is effective for the profile. About $70 \%$ of the middle section is effectively correct to below 0.003 (in). The maximum error is 0.0062 (in) in the progress. After the improved method, measure the shrinkage width of the workpiece. Compared with the product of the traditional process, the widest area is $6.37 \mathrm{~mm}$ shrink to $6.29 \mathrm{~mm}$. The shrinkage is about $1 \%$. Compared with the previous result is $5 \%$, the improvement plan has been optimized the outcomes very much. 


\section{Declarations}

\section{Ethical approval}

Since the study is performed at a relevant lab, there is no need for ethical approval. Additionally, the paper's main data is not published elsewhere.

\section{Consent to participate}

All authors declare that have agreed for authorship, have read and approved the manuscript, and have given the consent for submission and subsequent publication of the manuscript.

\section{Consent to publish}

All authors are consenting to publish this article with its included data in The International Journal of Advanced Manufacturing Technology and approve its final version.

\section{Authors' contributions}

All authors contributed equally to the generation and analysis of experimental data, and the development of the manuscript.

\section{Funding}

This work was financially funded by INTAI Technology Corp.

\section{Competing interests}

The authors declare that they have no competing interests.

\section{Availability of data and materials}

The authors confirm that the data supporting the findings of this study are available within the article.

\section{References}

1. Li F (2017) Jürgen Eckert. Optimization of the Hot Forging Processing Parameters for Powder Metallurgy Fe-Cu-C Connecting Rods Based on Finite Element Simulation. Metallurgical and Materials Transactions A volume 48:6027-6037

2. Zhuang W, Han X, Xu LHuM, Chen M (2019) FE prediction method for tooth variation in hot forging of spur bevel gears. J Manuf Process 38:244-255

3. A.Chamanfar HS (2019) .Misiolek. Development and validation of a finite-element model for isothermal forging of a nickel-base superalloy. Materialia 6:100319 
4. Panuwat Soranansri S, Yanil KS (Finite Element Modeling of Shrink-Fit Design for Improvement of Die-Service Life in Hot Forging Process of a Bevel Gear. Materials Today: Proceedings 2019) ;17(4):1711-1719

5. Michal Nytra P, Kubı'k (2020) Jindr`ich Petrus``ka, and Frantis` ek S` ebek. A Fully Coupled Thermomechanical Damage Analysis of Hot Closed Die Forging Using Finite Element Modeling. J Mater Eng Perform 29:8236-8246

6. Kumar SDinesh, Purushothaman K, Chandramohan D, Dushyantraj MMohinish (2020) T.Sathish. ANN-AGCS for the prediction of temperature distribution and required energy in hot forging process using finite element analysis. Materials Today: Proceedings ;21(1): 263-267

7. Song HN, Kim YS, Joun MSThe effects of theoretical models of materials and die on finite element

8. predictions in (2021) a forging process of aluminum scroll. SAGE Journals 2:235

9. Xiaowen, Wang, Lin Hua (2021) Finite element study on microstructure evolution and grain refinement in the forging process of automotive front axle beam. The International Journal of Advanced Manufacturing Technology 114:1179-1187

10. Misael Dalbosco PD, Schmitt L, Pinotti, Denis Boing (Improving fatigue life of cold forging dies by finite element analysis: Acase study. Journal of Manufacturing Processes 2021). ;64:349-355

11. Marek Hawryluk J, Ziemba (2018) Application of the 3D reverse scanning method in the analysis of tool wear and forging defects. Measurement 128:204-213

12. Hawryluk M, Ziemba J, Zwierzchowski M, Janik M (2021) Analysis of a forging die wear by 3D reverse scanning combined with SEM and hardness tests. Wear 476:203749

13. Kuan-YuSu T, Welo, Jyhwen Wangc (2018) Improving Friction Drilling and Joining through Controlled Material Flow. Procedia Manufacturing 26:663-670

14. Seong-Won, Lee (2019) Jae-Wan Jo, Man-Soo Joun, Jung-Min Lee. Efect of Friction conditions on Material Flow in FE Analysis of Al Piston Forging Process. Int J Precis Eng Manuf 20:1643-1652

15. Shen Z, Li WY, Ding Y, Hou W, Liu XC, Guo W, Chen HY, Liu X, Yang J, Gerlich AP (2020) Material flow during refill friction stir spot welded dissimilar Al alloys using a grooved tool. J Manuf Process 49:260-270

16. Medical Devices Companies n.d., ECHELON CONTOUR Curved Cutter, Medical Device Business Services , accessed 21 July 2021, < https://www.jnjmedicaldevices.com/en-EMEA/product/echeloncontour-curved-cutter-stapler>

\section{Figures}


(a)



Figure 1

Configuration of the medical surgery curve cutter stapler[16]

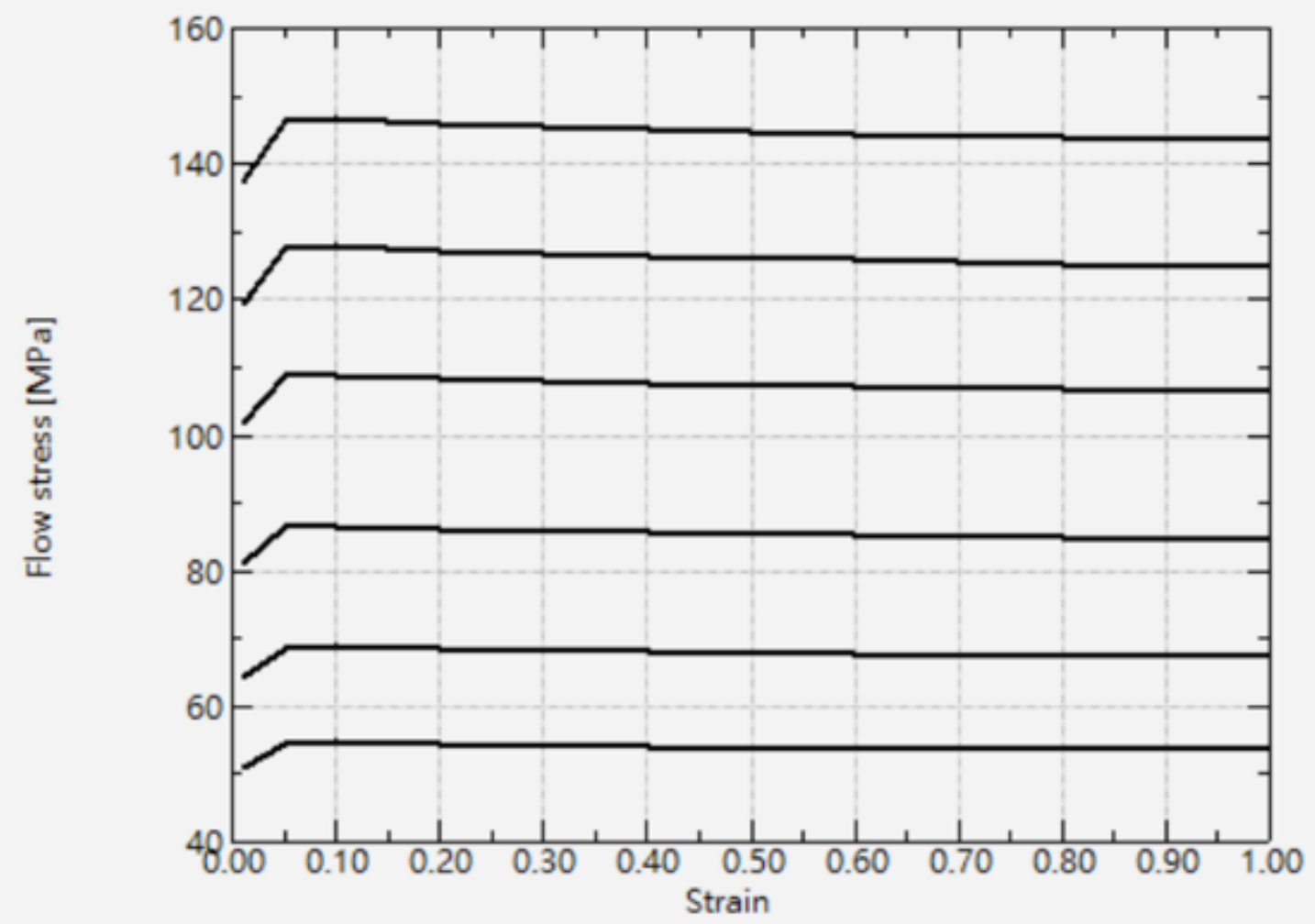

Figure 2 
Stress-strain curve of aluminum alloy AA7075

(a)

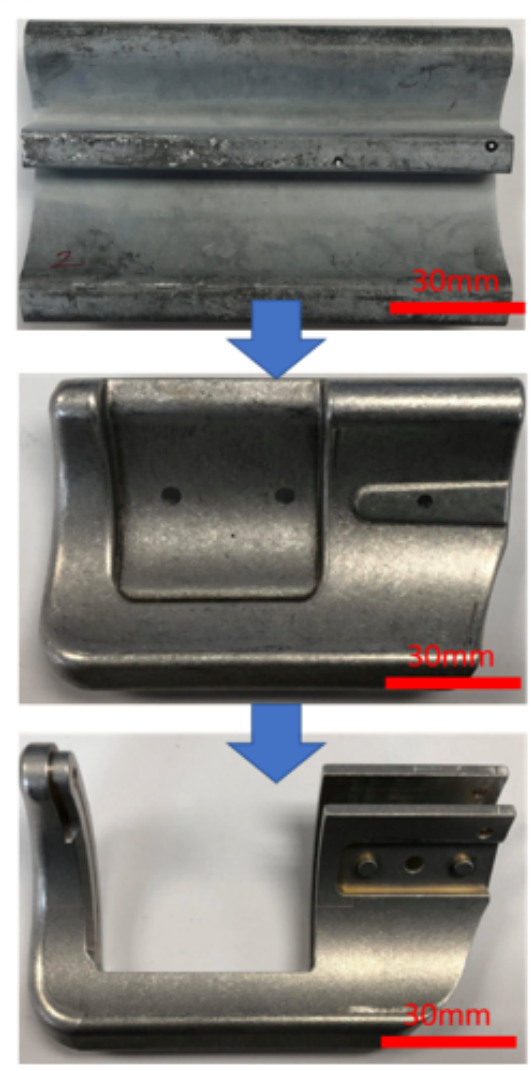

(b)

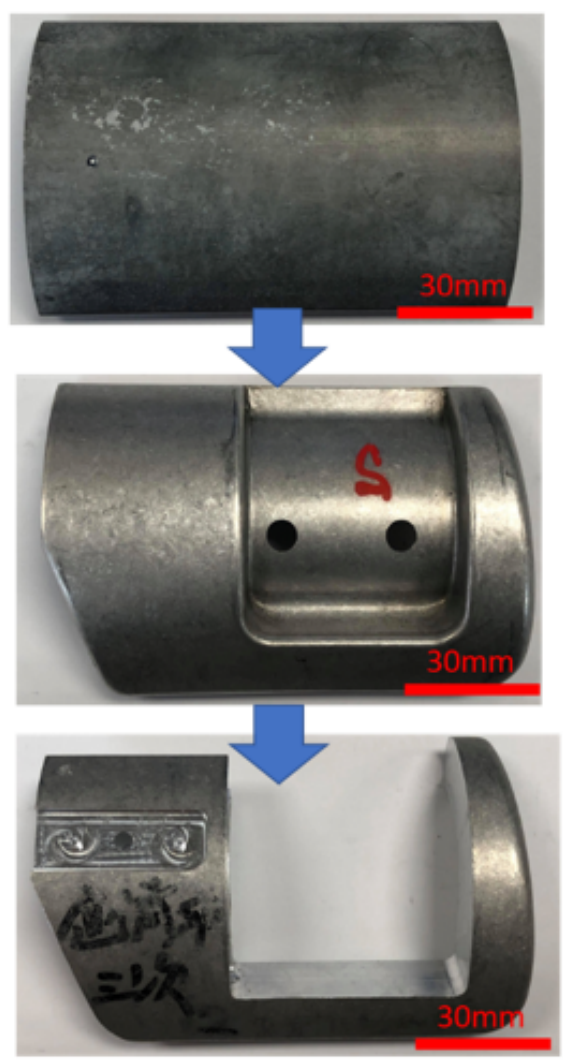

(c)

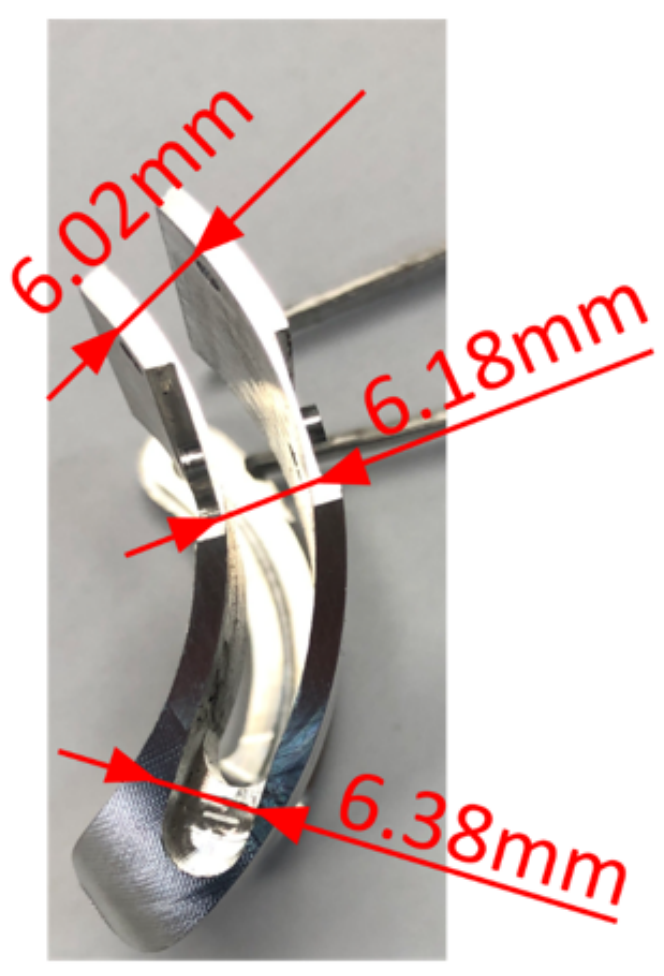

Figure 3

(a) The aluminum extrusion process of the curve cutter head (front side) (b) The aluminum extrusion process of the curve cutter head (contrary side) (c) The defects caused by the residual stress 


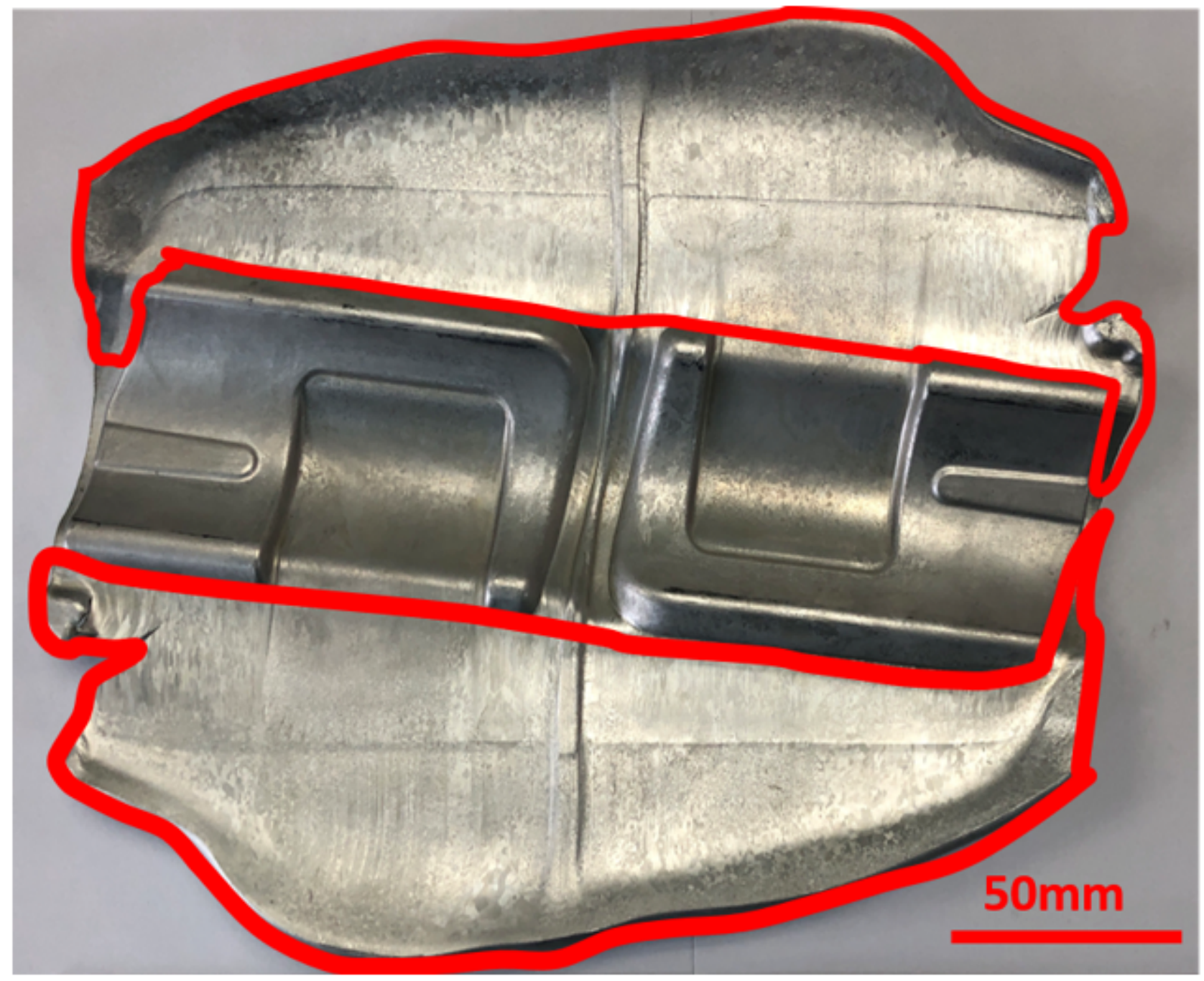

Figure 4

The defects of traditional forging without precision volume distribution 


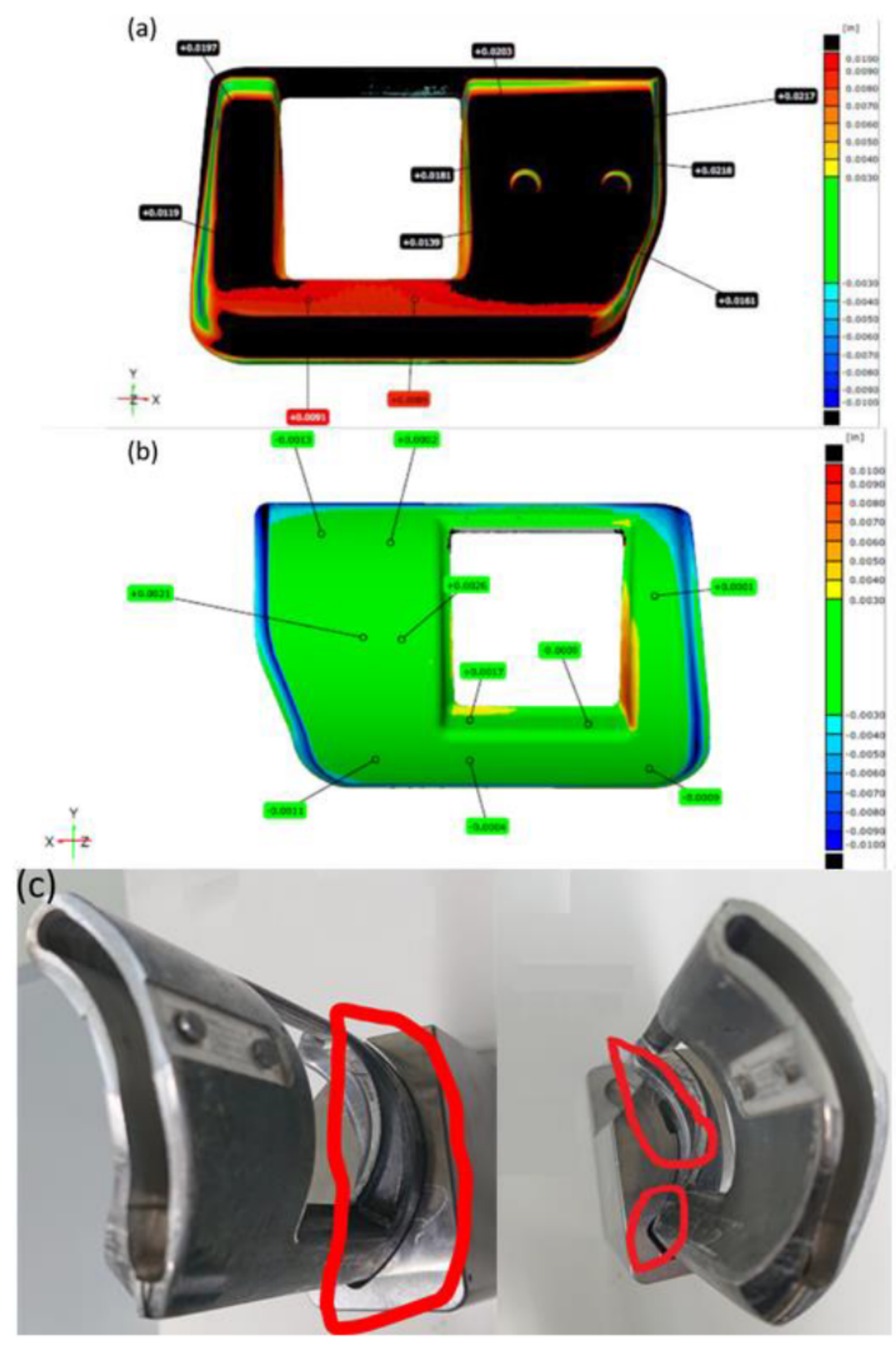

Figure 5

3D scanning of forging process contour defect of traditional forging product (a) front side (b) contrary side (c) the real workpiece defects 


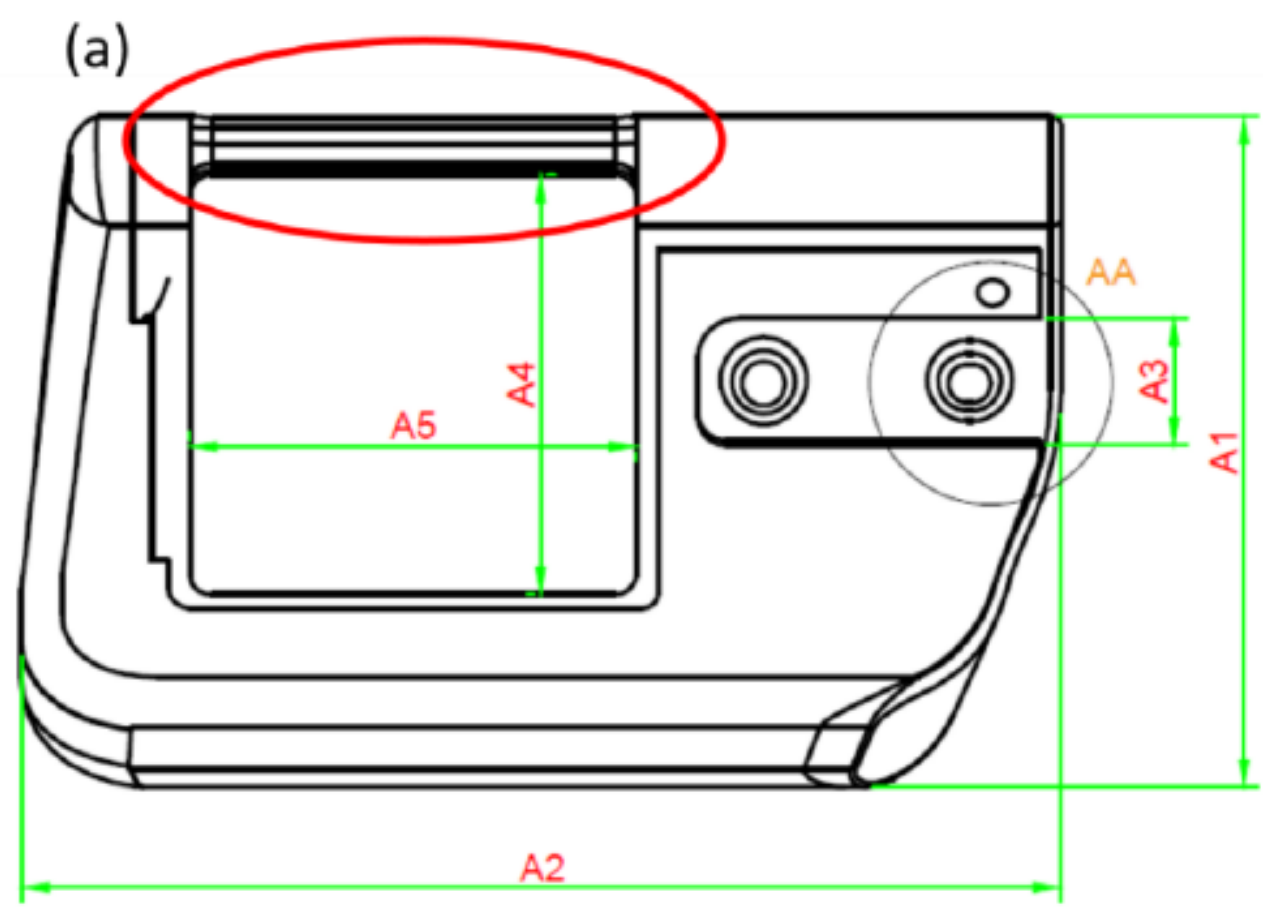

(b)

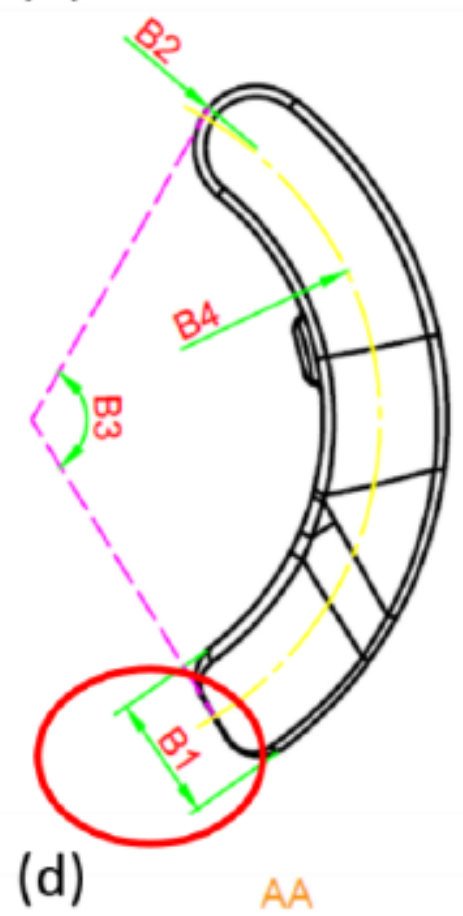

(c)
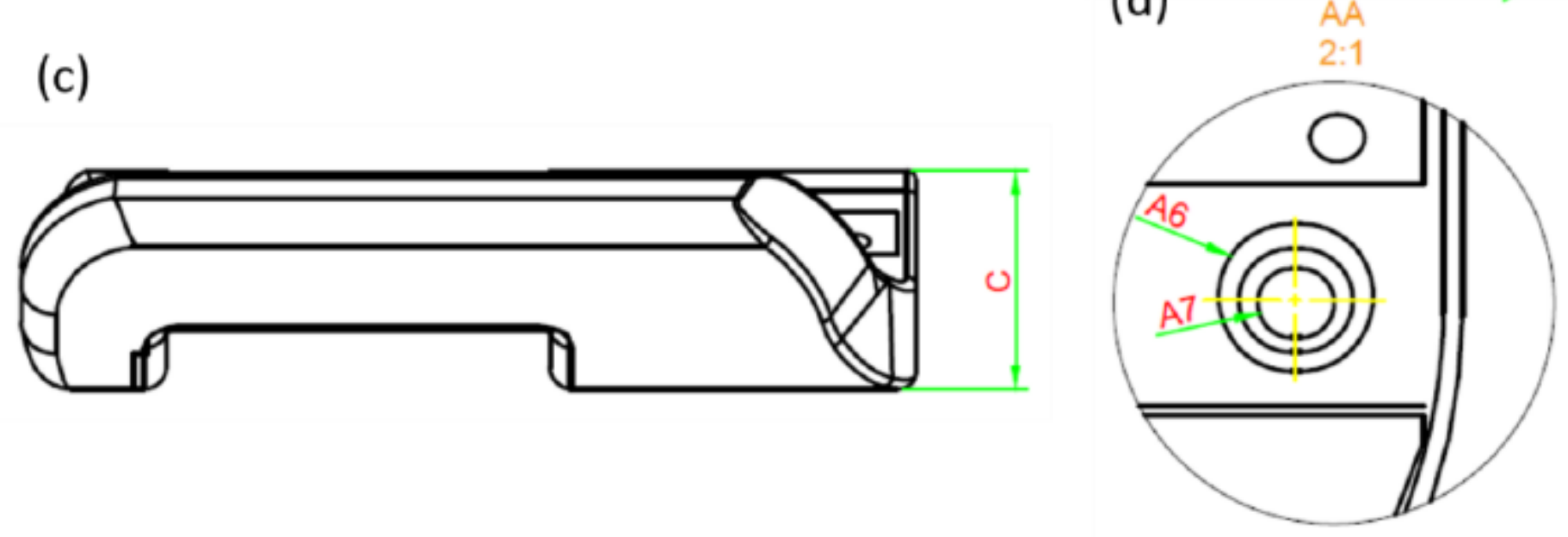

Figure 6

Engineering drawing of the curve cutter head, showing the primitive dimensions with the different views.

(a) Top view (b) Side view (c) Part size of right view(d) Partially enlarged size 


\section{Preforming $\Rightarrow$ Bending $\Rightarrow$ Rough forging $\Rightarrow$ Finish forging}

Optical photo

(a)

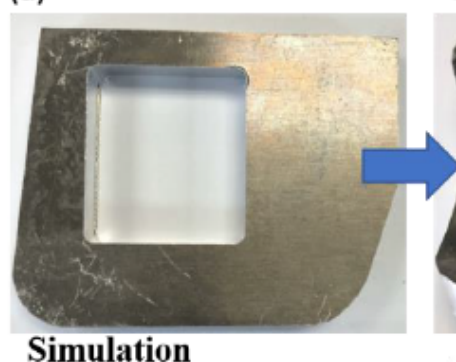

\section{Simulation}

(c)

(b) (d)

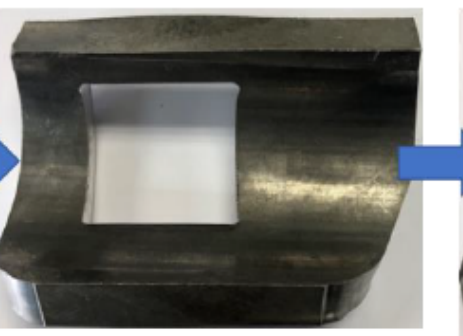

\section{(c)}
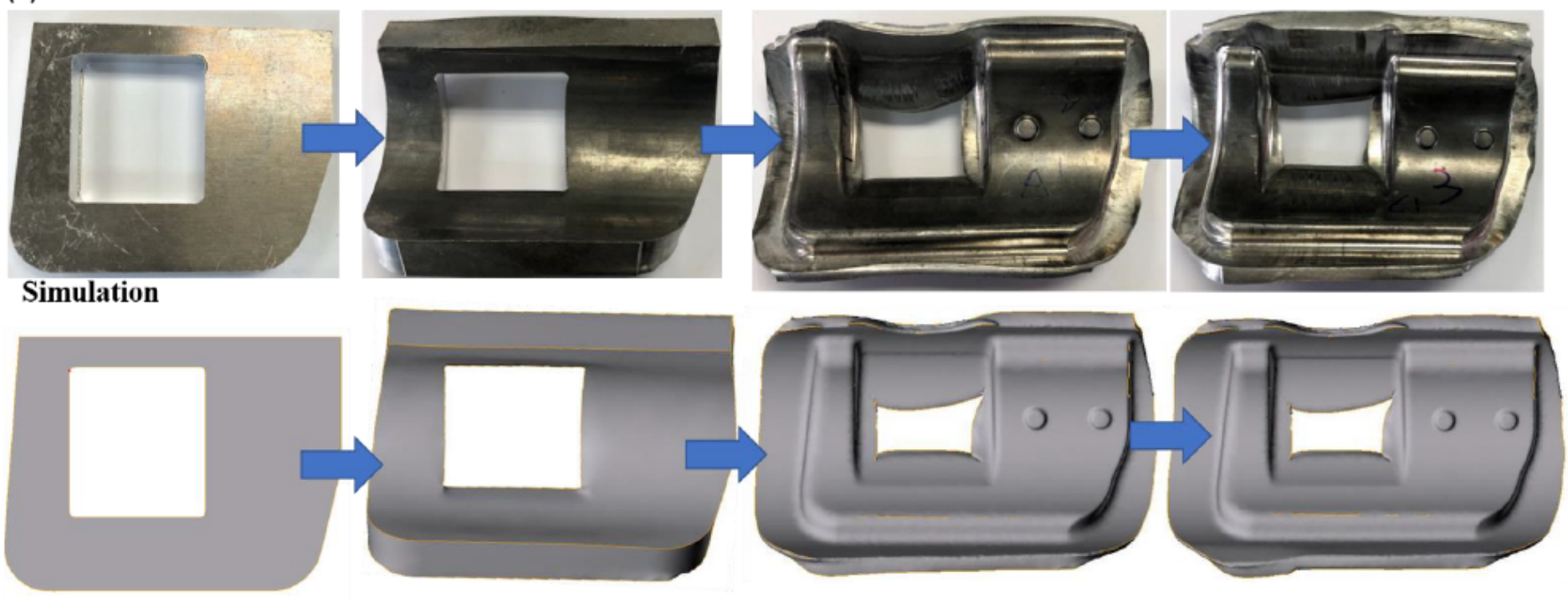

Figure 7

Proposed fabrication stages of forming process design in hot controlled flow forming process for minimization of excessive outflow and the resultant residual stress to maintain surface profile tolerance. (a) the preform of laser cutting (b)bending (c)rough forging (d)finish forging

(a)

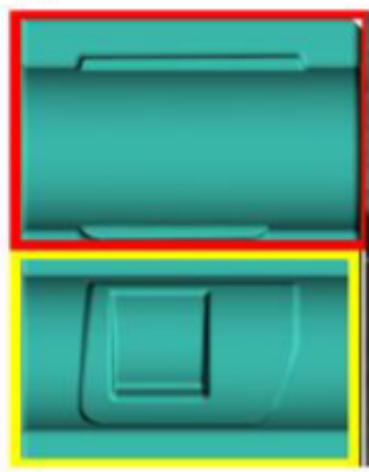

(c)

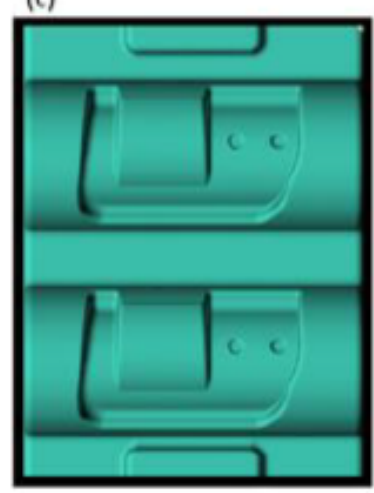

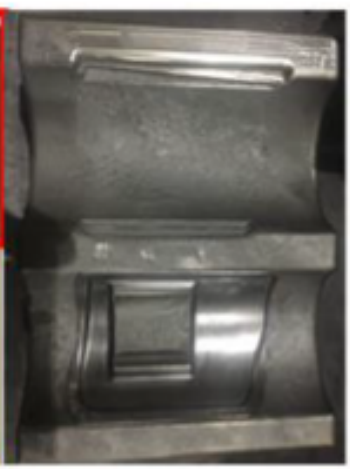

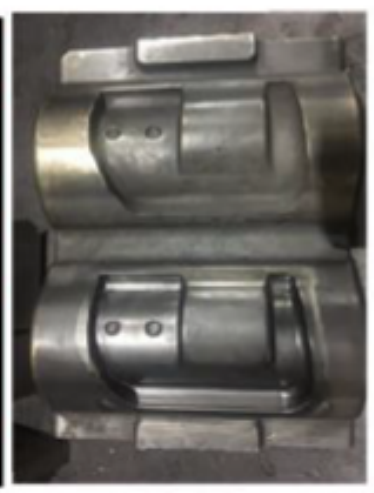

(b)

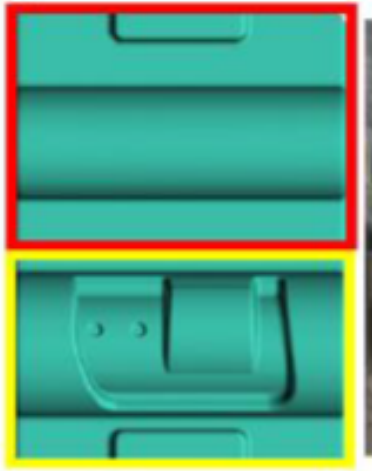

(d)

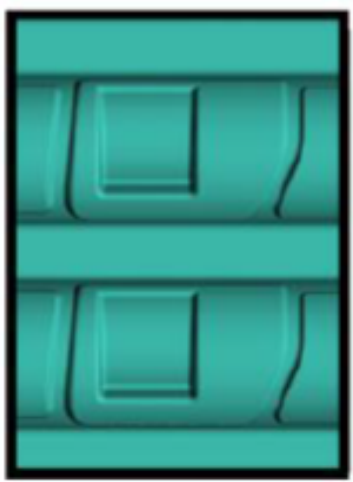

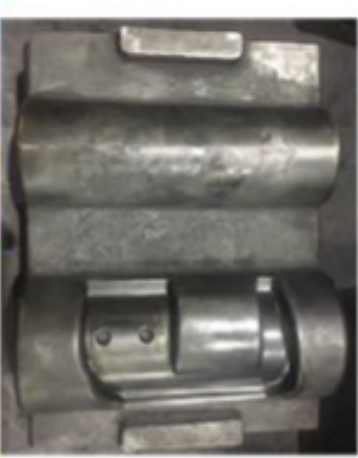

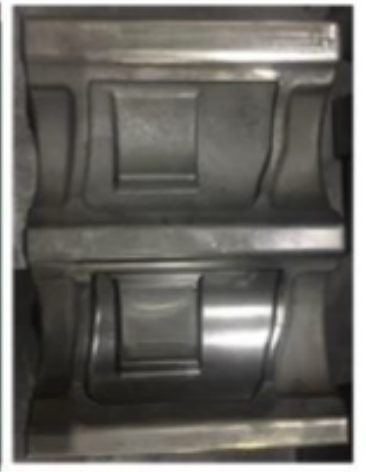

Figure 8 
Tooling designs. (a) Buttom die of bending and rough forging (b) Top die of bending and rough forging (c) Buttom die of finish forging (d)Top die of finish forging

(a)

(b)

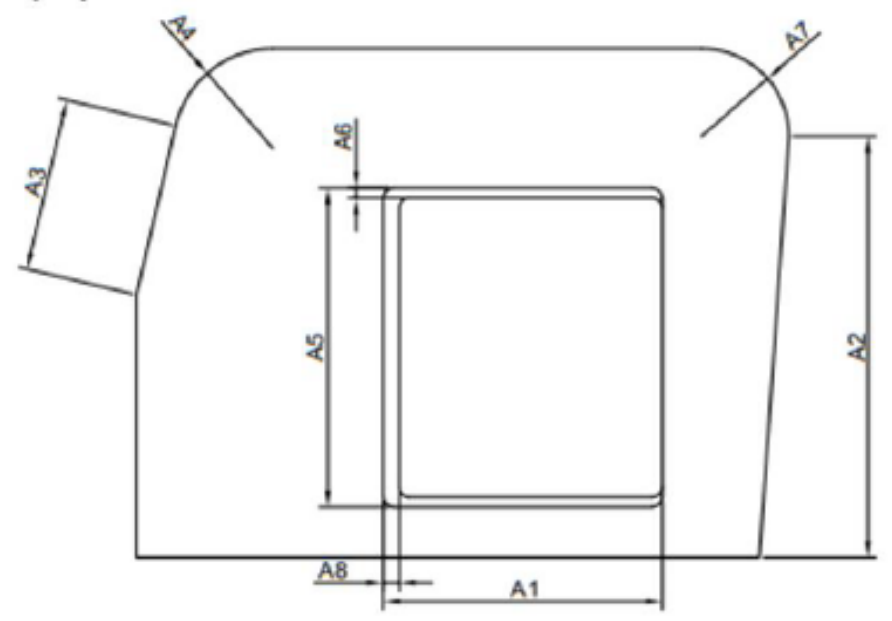

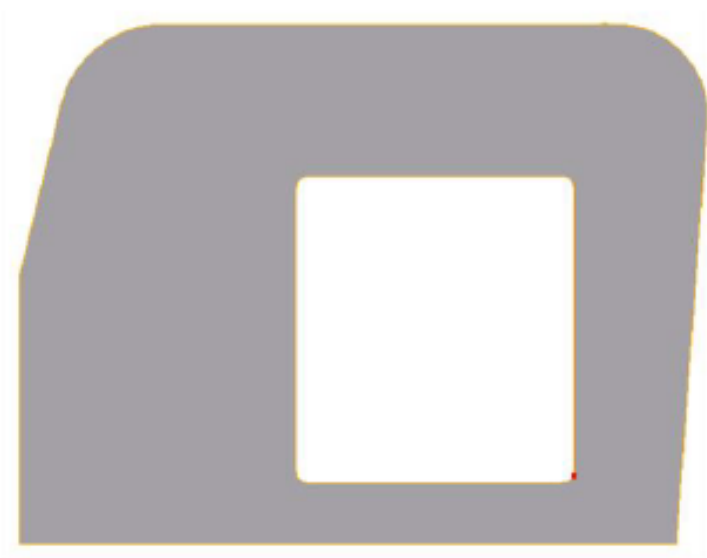

(c)
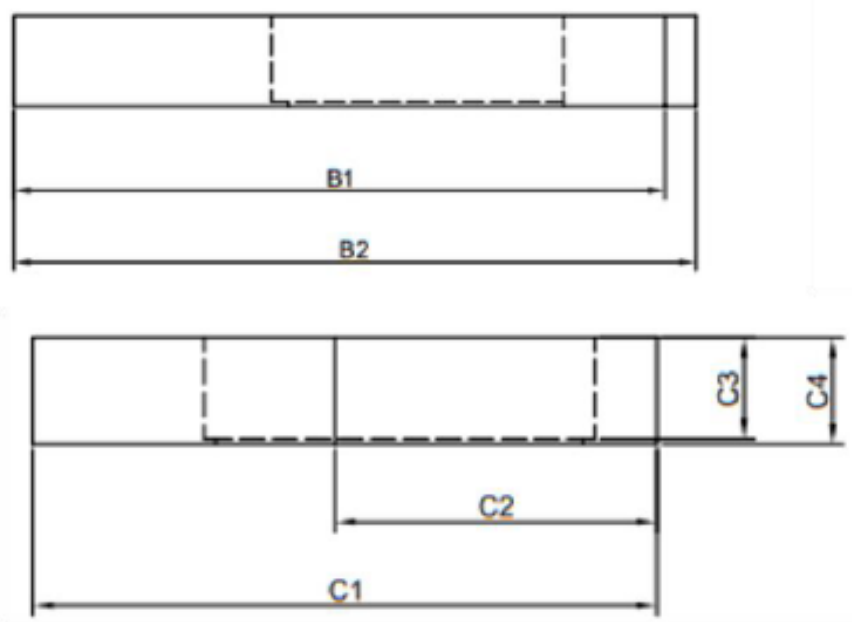

Figure 9

Preforming designs for the medical tool (a)the optical photo and simluation photo of the workpiece (b) the top view-dimension (c) the side view-dimension 


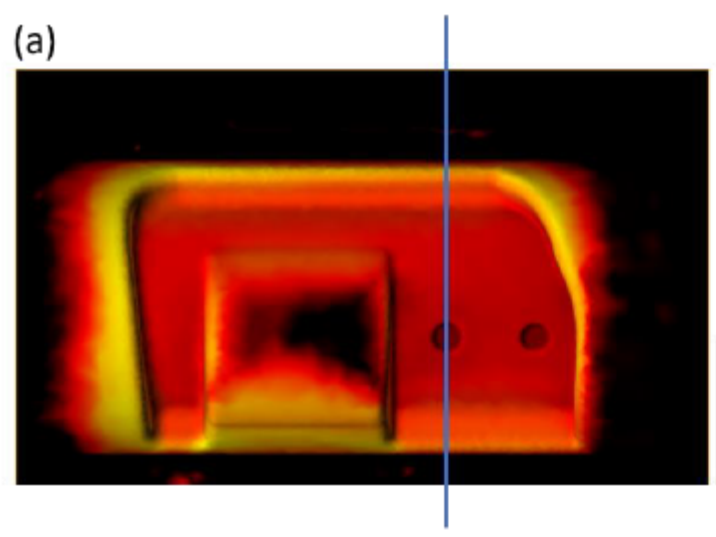

(b) 380
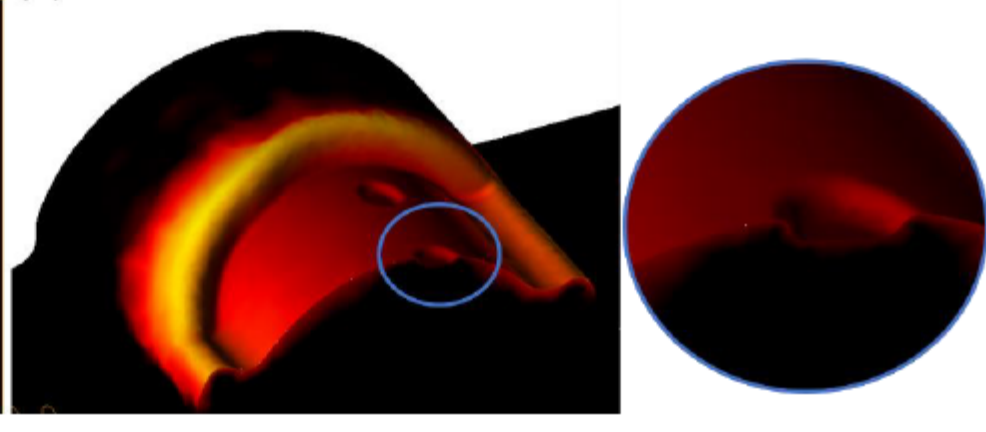

\section{Figure 10}

The analysis of the temperature of the workpiece (a) top dies of rough forging (b) cross-section of local feature area. 
$80 \%$ stroke

(a)

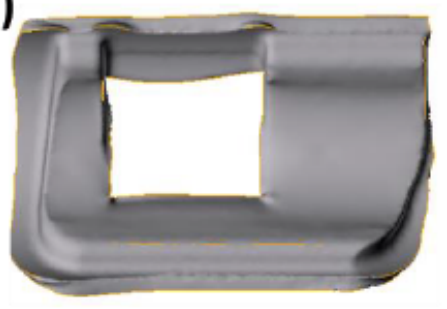

(b)
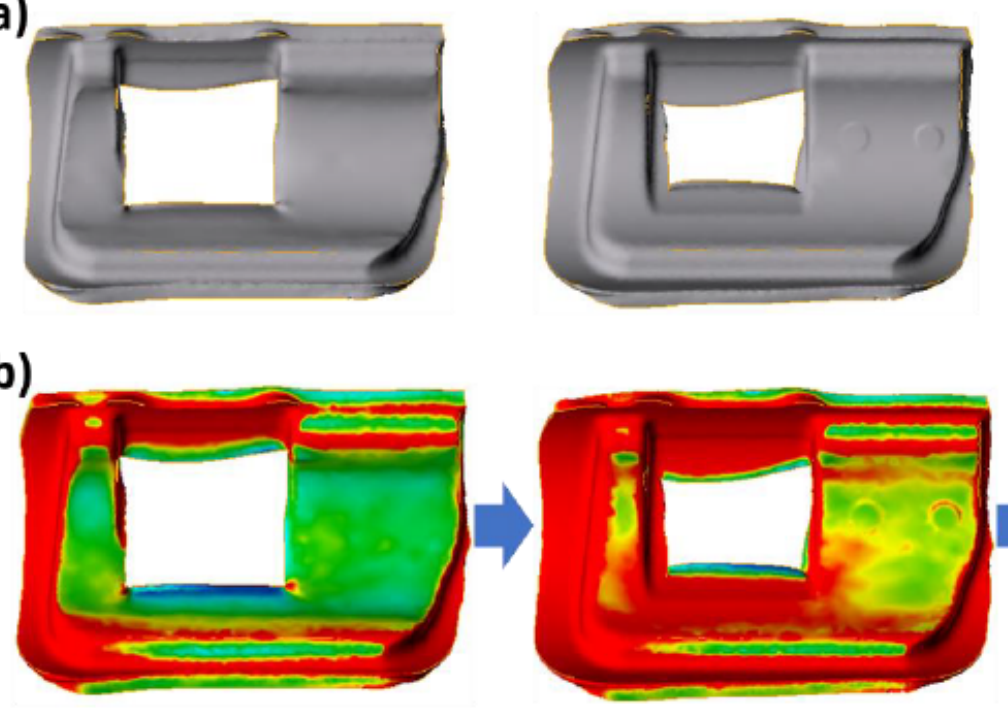

$90 \%$ stroke

$100 \%$ stroke

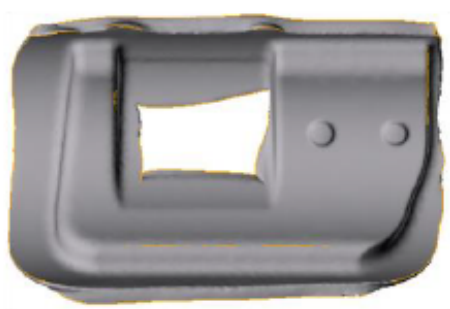

Effective Plastic Strain
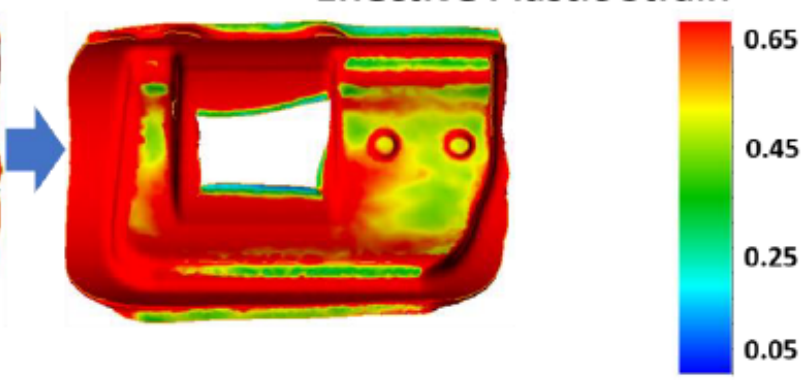

Effective Stress(MPa)

(c)
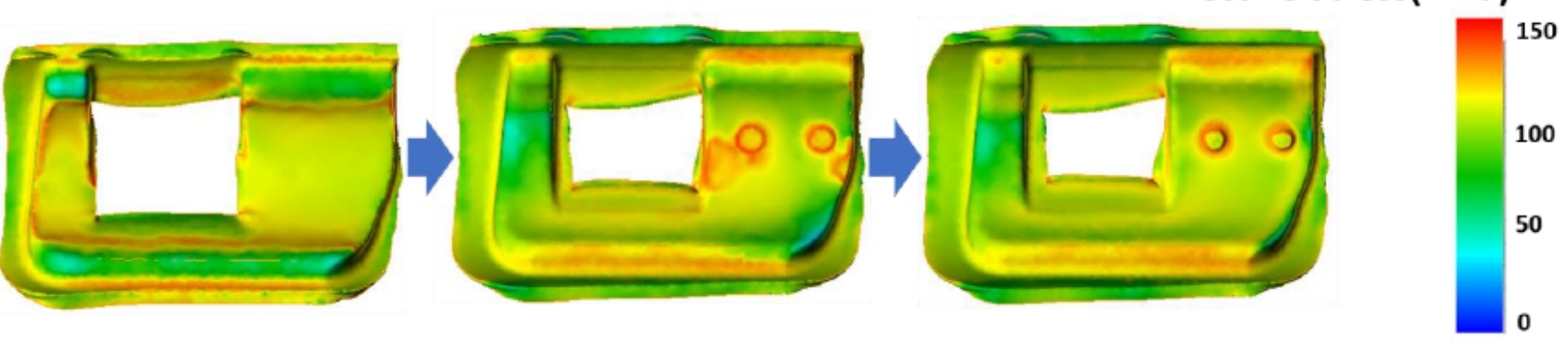

Temperature $\left({ }^{\circ} \mathrm{C}\right)$

(d)
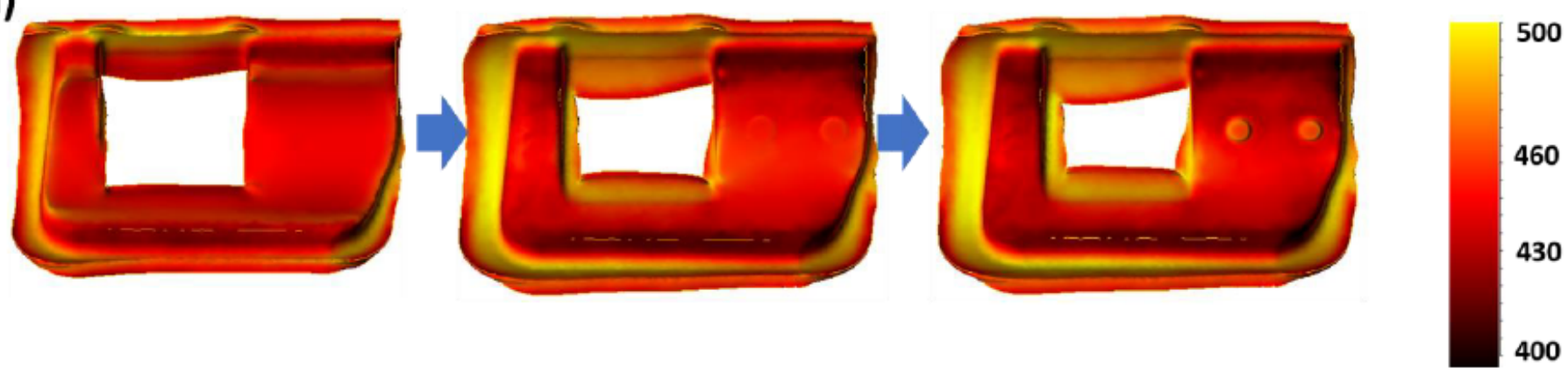

\section{Figure 11}

The simulated outcomes of the workpiece. (a) The process at different forging steps (punch stroke). (b) Effective stress. (c) Effective plastic strain. (d) The temperature. The conditions of the punch stroke of $80 \%, 90 \%$, and $100 \%$ are presented from left to right respectively. 

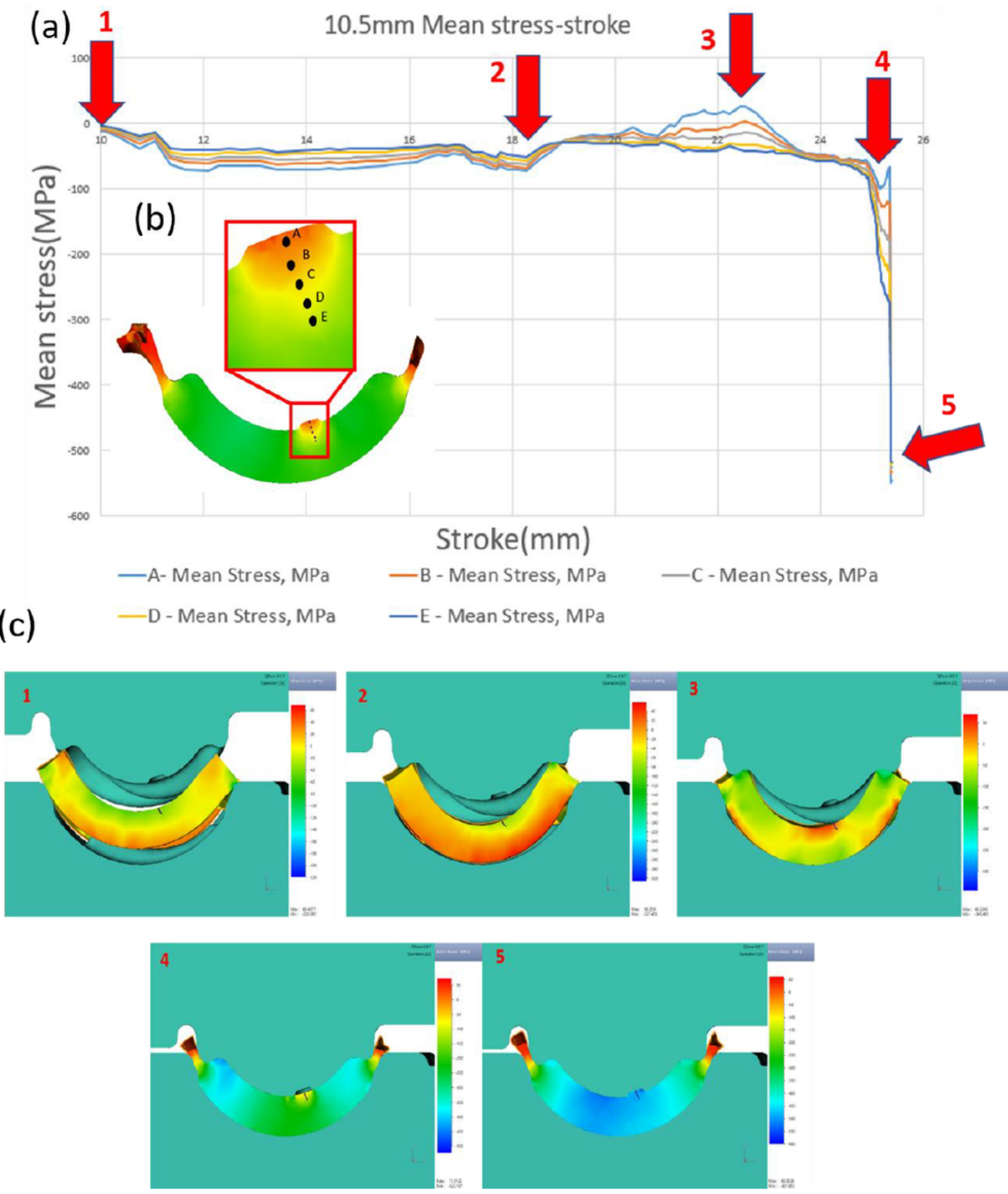

Figure 12

(a) Stress distribution diagram of medical tools (b) Distribution diagram of sampling points (c) comparison diagram of the step of forging process of in the software 


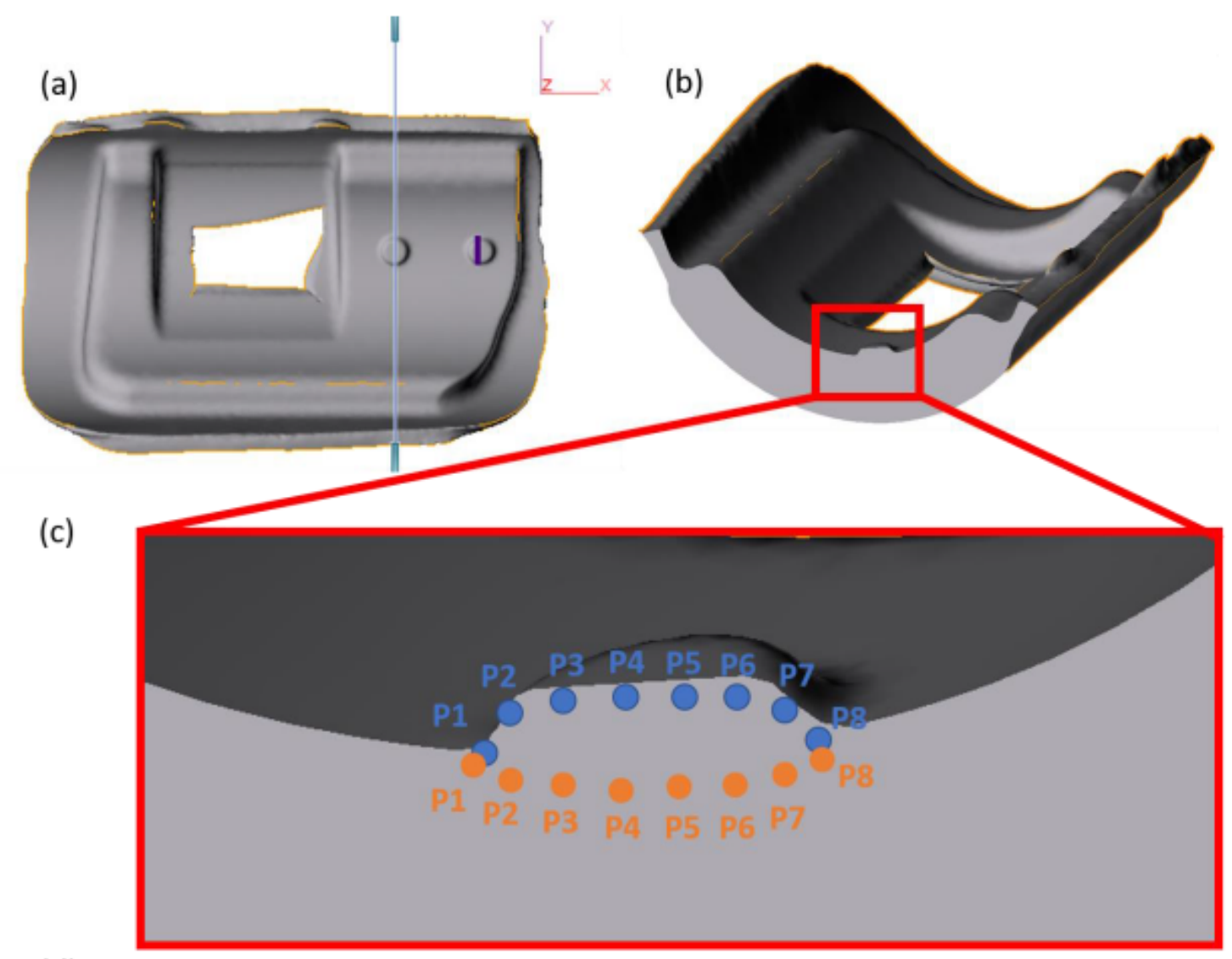

(d)

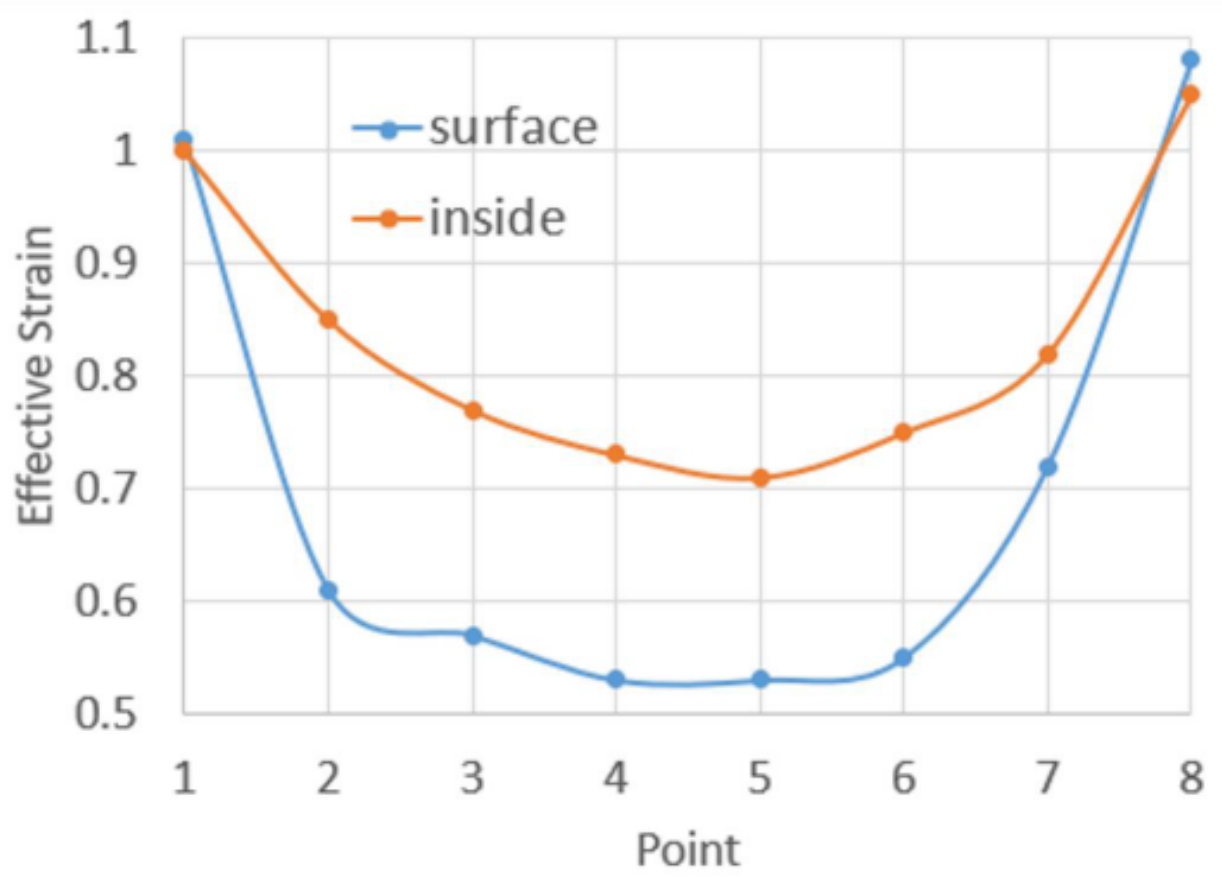

Figure 13

Schematic location of points on curve cutter $(a) \sim(c)$ the region of investigation (d) the plastic strain of the curve cutter's surface and inside 
(a)

\section{Mean stress with different thickness}

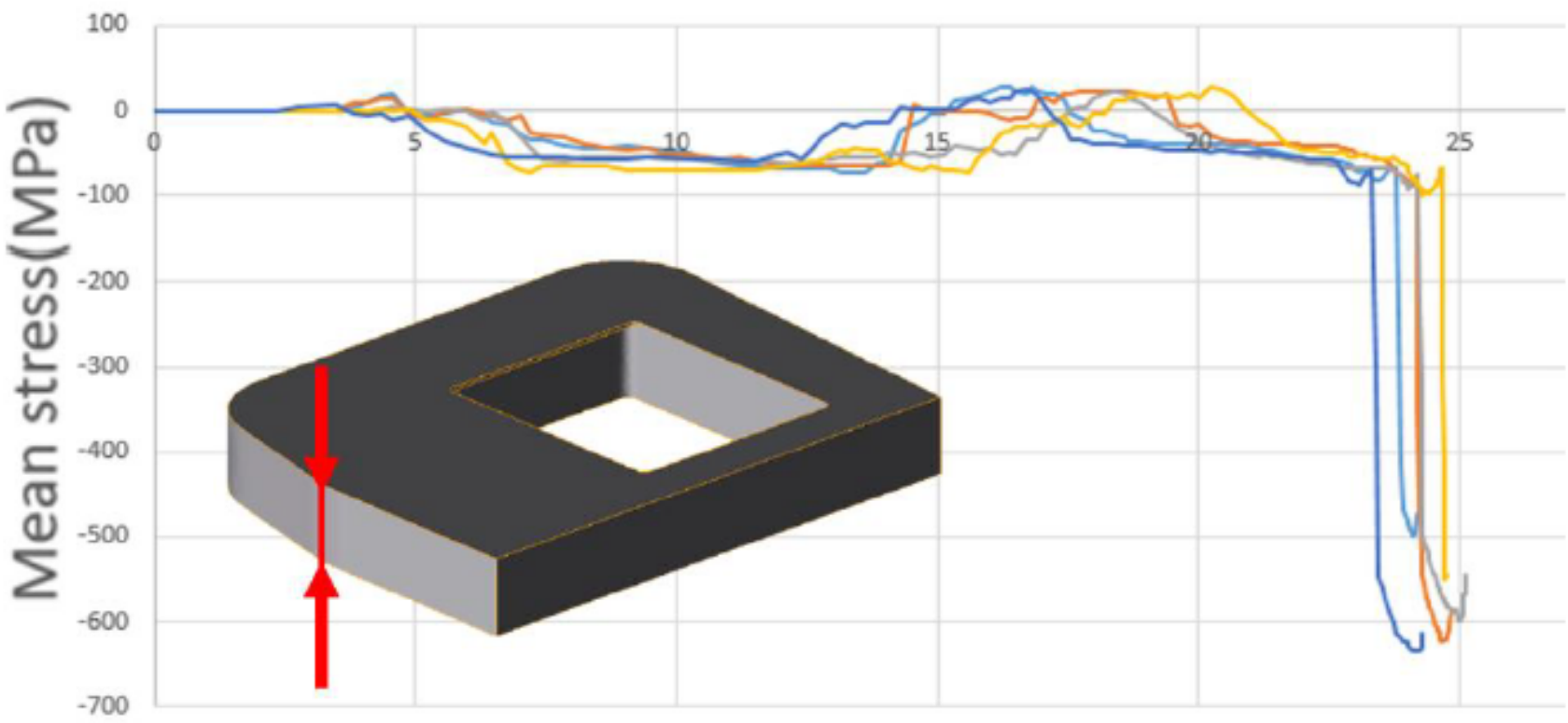

Stroke

(b)

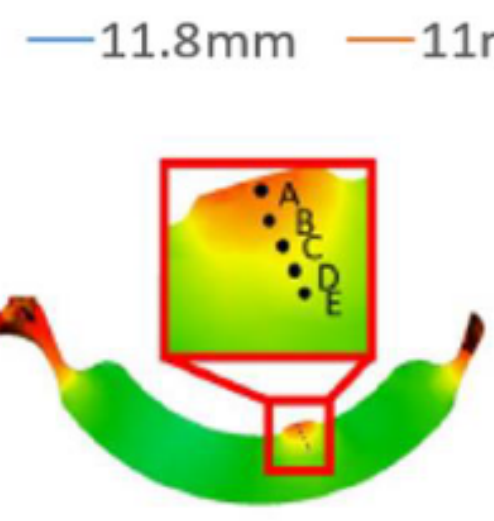

(c)

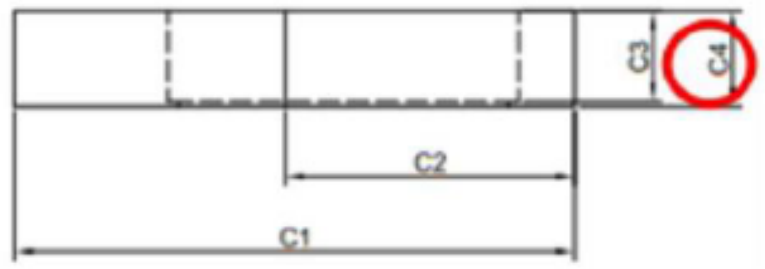

(d)

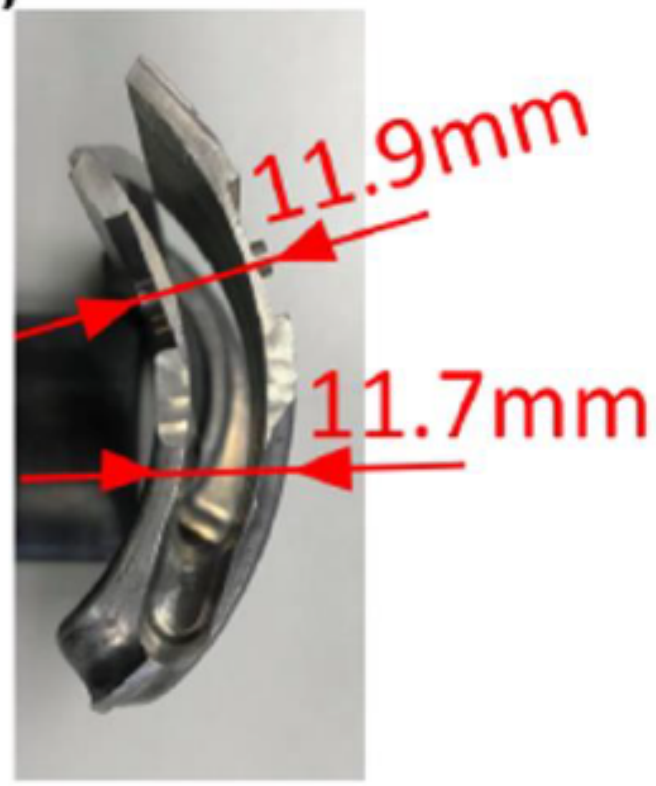

\section{Figure 14}

Stress analysis of different thicknesses for Rough forging (a) stress and thickness graph of workpiece (b) analysis diagram of the five points (c) Thickness variable of the workpiece (d) the shrinkage caused by residual stress 
(a)

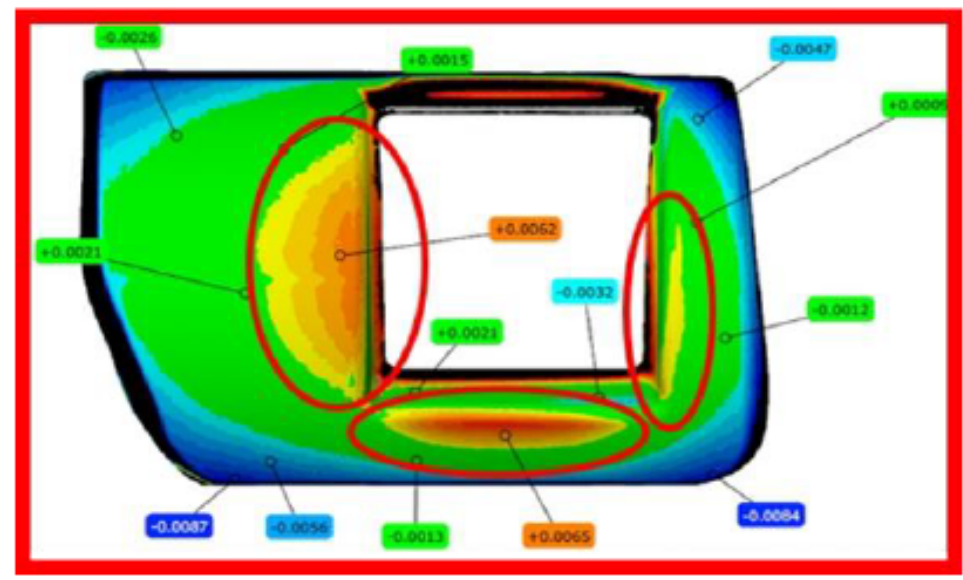

(c)

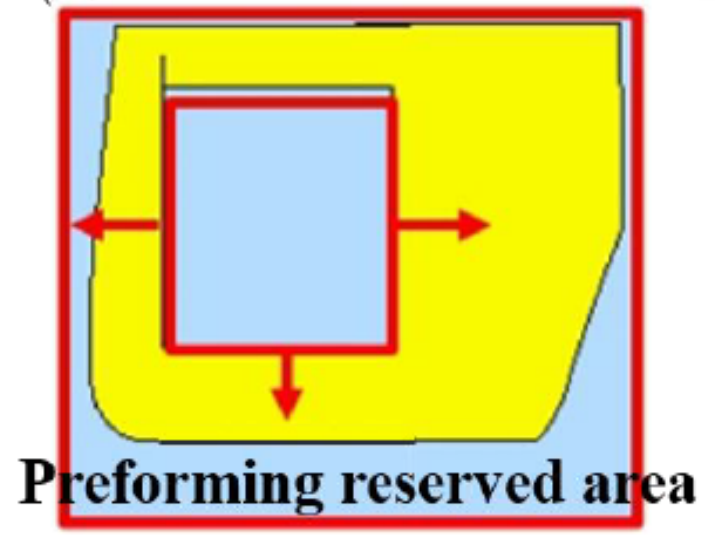

(e)

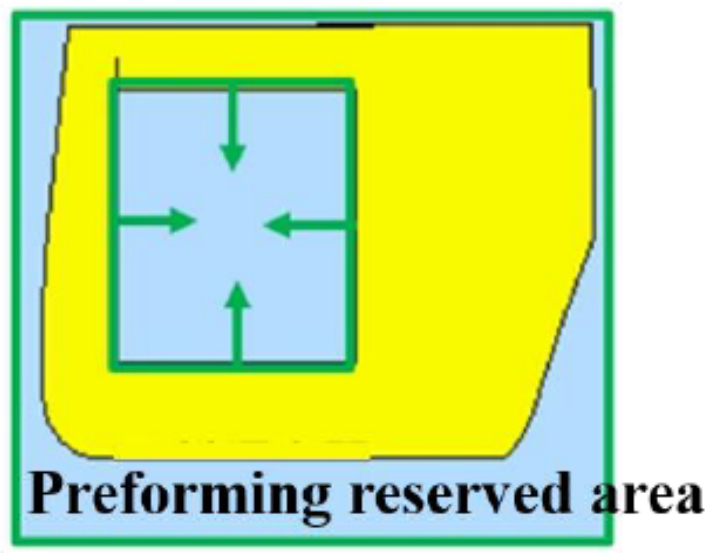

(d)

(b)

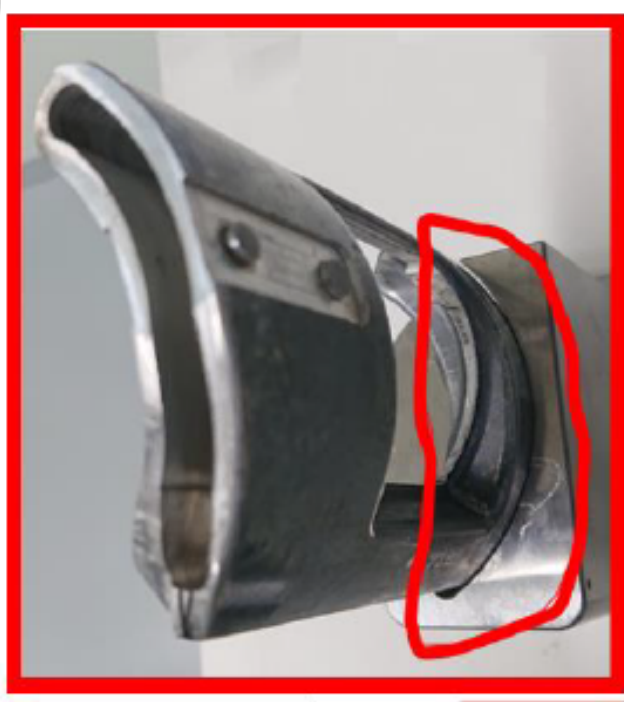

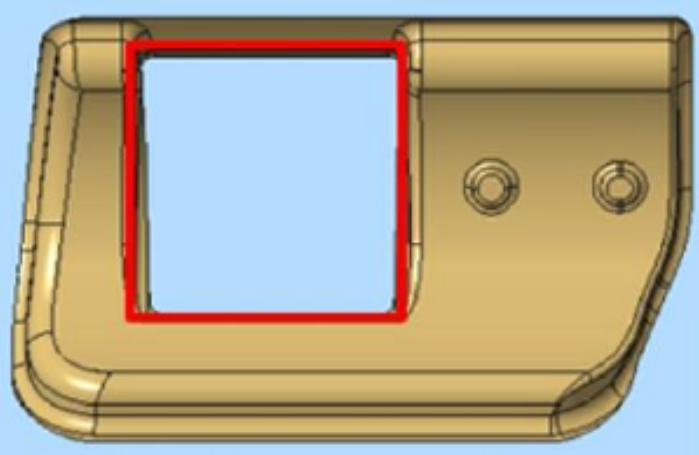

Preforming reserved area

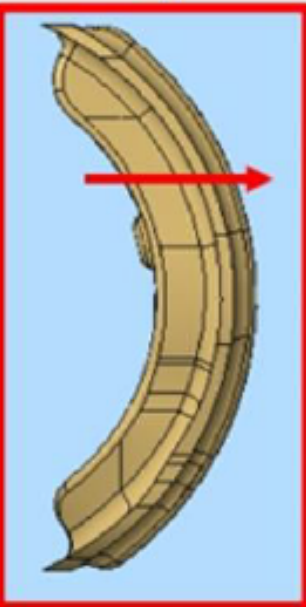

\section{Figure 15}

Medical curved tool contour improvement plan (a) diagram of the 3D overlay scanning area with the condition of poor contour(b) the defects caused by the poor contour (c) Insufficient blank space at the workpiece (d) Empty blank Schematic diagram of defects caused by insufficient parts (e) diagram of improved design 
(a)

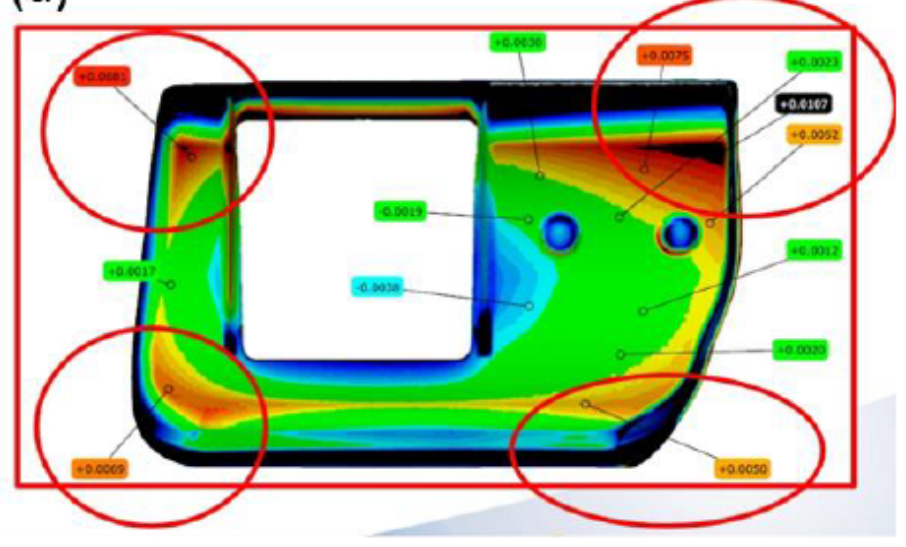

(c)

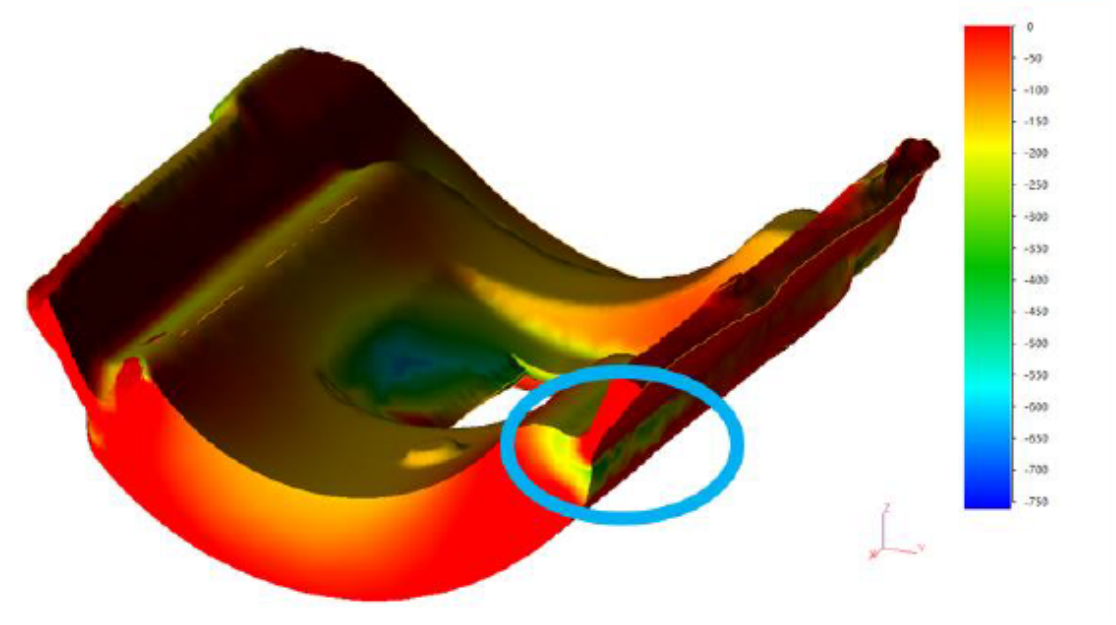

(b)

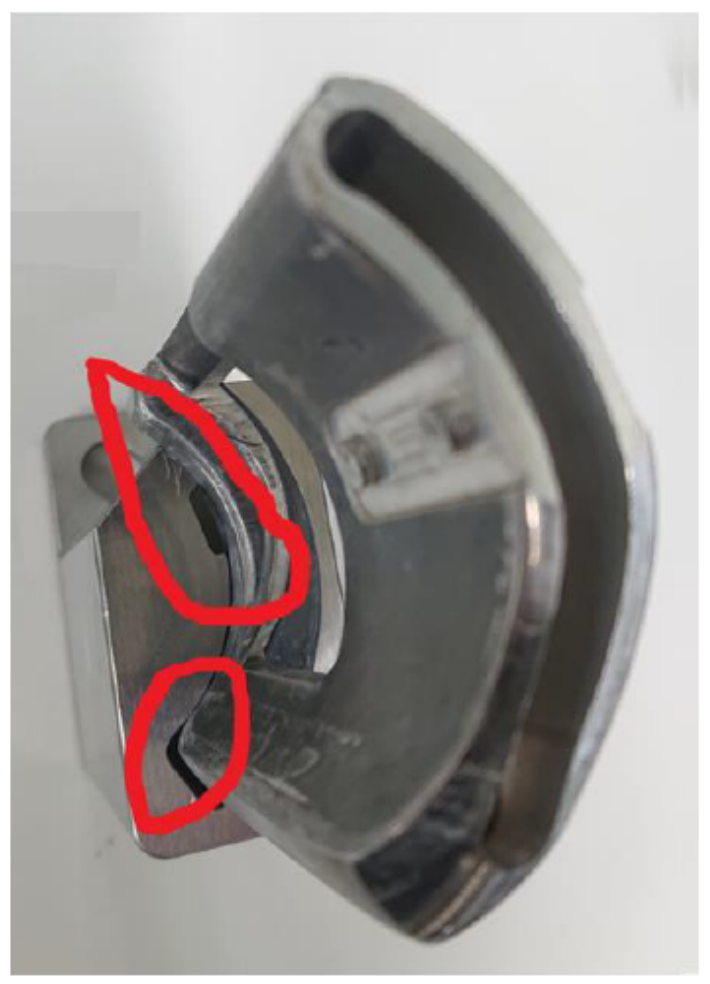

Figure 16

Defect analysis of forging the profile of medical curved cutter (a) defect region of finish forging (b) forgings cannot be placed in the quantitative jig (c) materials flowing of finish forging 

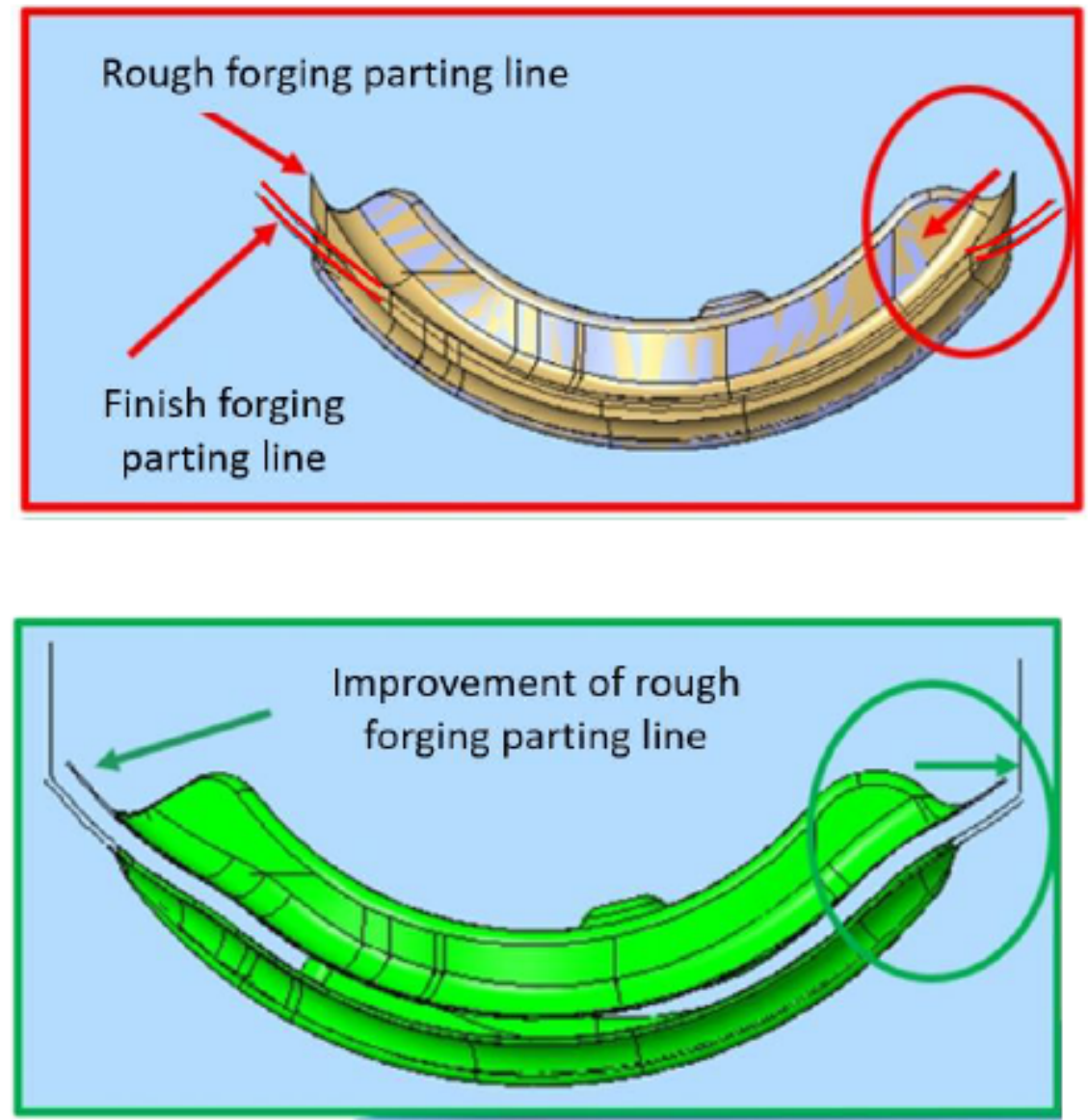

Figure 17

Medical curved cutter forging profile improvement plan (a) Sketch of rough forging and fine forging parting surface (b) Sketch of changing rough forging parting surface 
(a)

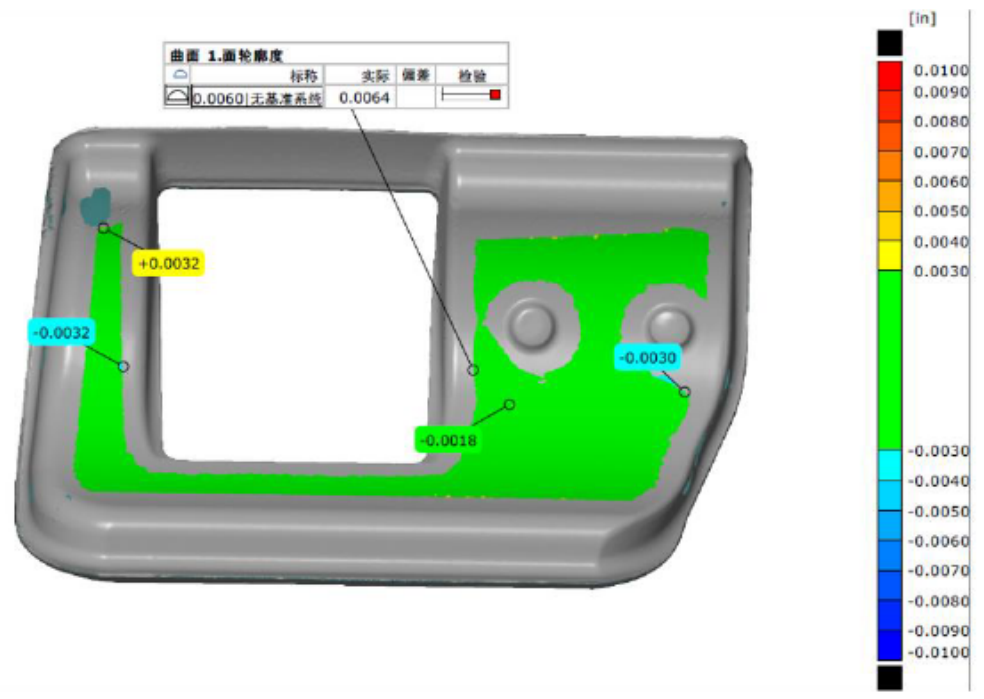

(b)

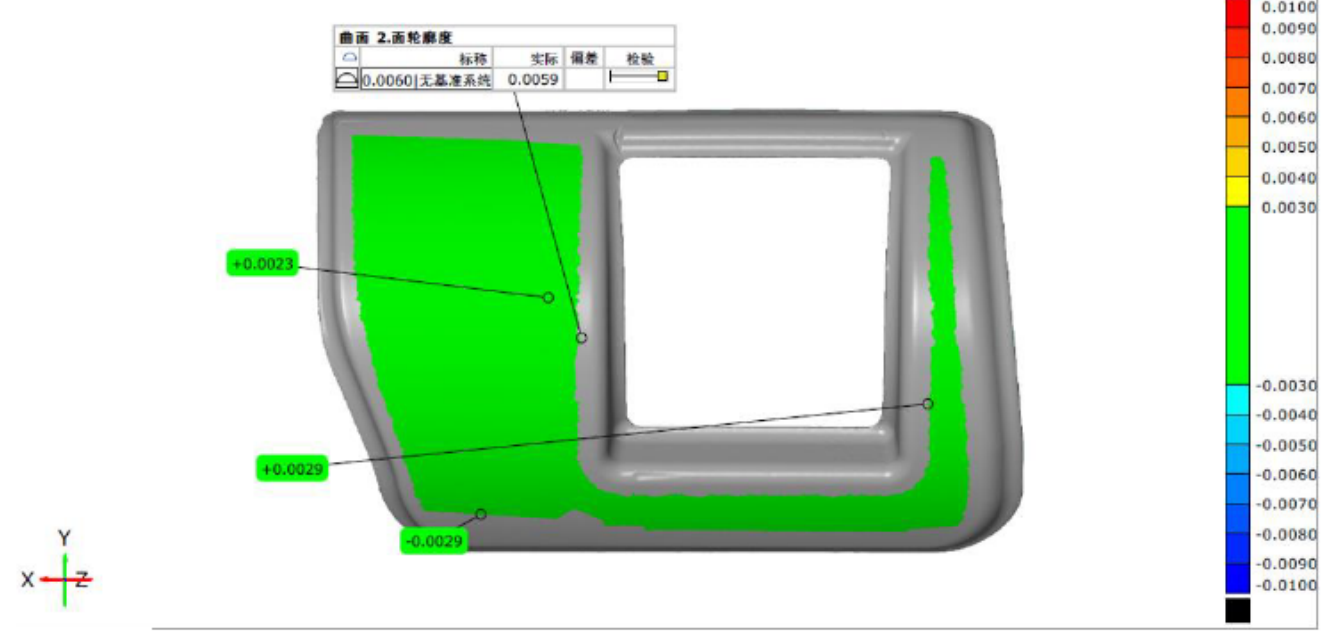

(c)

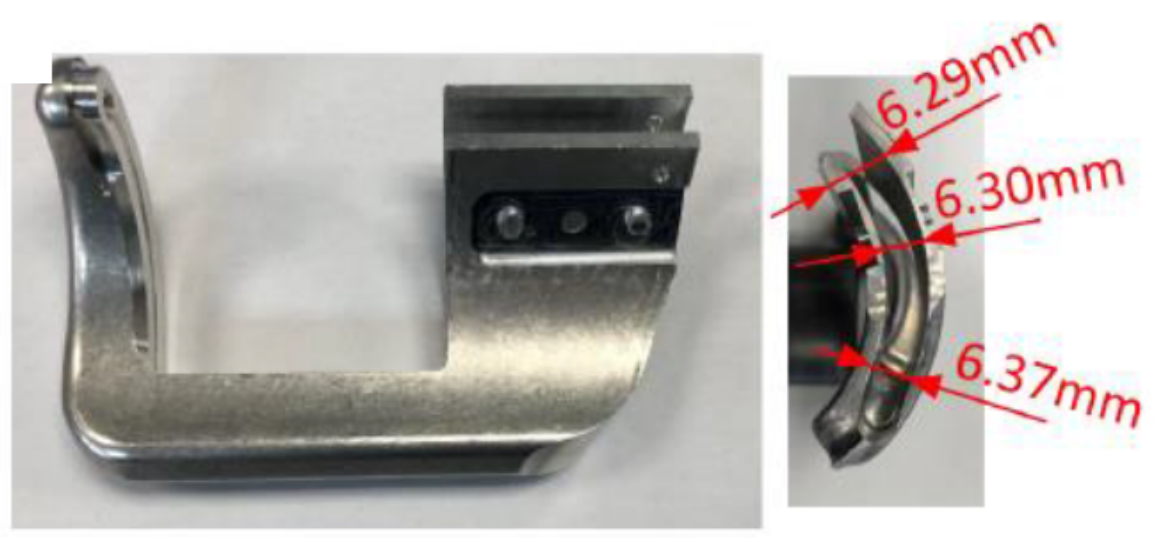

Figure 18

The influence of controlled material flowing process(a) the surface profile of front side (b) the surface profile of back side (c) the shrinkage caused by residual stress. 